\title{
PRONY FILTRATION OF SEISMIC DATA: THEORETICAL BACKGROUND
}

\author{
Georgy Mikhailovich Mitrofanov ${ }^{1}$ and Viatcheslav Ivanovich Priimenko² \\ Recebido em 5 julho, 2010 / Aceito em 19 dezembro, 2011 \\ Received on July 5, 2010 / Accepted on December 19, 2011
}

\begin{abstract}
There is discussed a new method for seismic data processing and technology of its use in solving geological and field tasks. This method is based on the Prony decomposition and selection of components of this decomposition in order to obtain images of seismic data corresponding to a narrow band of frequencies. Therefore, the method can be called Prony filtration. Its closest analogue is a bandpass filtration. However, Prony filtration method provides higher resolution of signal image with respect to the time variable. Also, the method allows to obtain a damping parameter corresponding to the frequency of filtration. This makes it possible to investigate changes in the damping parameter as a function of the frequency. Special attention is paid to three points: (i) theoretical foundations of the Prony decomposition to obtain stable estimates of the Prony spectra for signals similar to seismic ones; (ii) use of Prony spectra in the signal filtration processing, i.e., construction of the Prony filtration algorithms; and (iii) description of the Prony filtration technology and examples demonstrating its capabilities in practice. Using simple examples, we introduce basic ideas of the technology, illustrating the main points that are important for the application of this method in the real seismic data processing. The results show good stability of the algorithm for different waveforms and in the presence of other signals and noise. We hope that this approach attracts the attention of specialists to the nonlinear Prony filtration method, as well as to aspects of its implementation in geophysical spectral analysis.
\end{abstract}

Keywords: Prony and Fourier transforms, spectral analysis, signal decomposition and filtration.

RESUMO. Neste artigo estamos discutindo um método novo para o processamento de dados sísmicos e sua utilização em vários problemas geológicos e geofísicos. 0 método é baseado na decomposição de Prony e seleção de componentes desta decomposição a fim de obter dados sísmicos correspondentes a uma faixa estreita de frequências. Portanto, o método pode ser chamado de filtragem de Prony. Seu melhor análogo é um filtro passa-faixa. No entanto, o método da filtragem de Prony oferece maior resolução de imagem de sinal em relação à variável temporal. Além disso, o método permite a obtenção de um parâmetro de atenuação correspondente à frequência de filtragem. Isto torna possível investigar mudanças no parâmetro de atenuação em função da frequência. Uma atenção especial é dada às dificuldades principais que podemos encontrar em processamento de dados sísmicos: (i) fundamentos teóricos da decomposição de Prony para obter estimativas estáveis do espectro de Prony para sinais semelhantes a sinais sísmicos; (ii) utilização do espectro de Prony no processamento de filtragem de sinais, ou seja, a construção de algoritmos da filtragem de Prony; e (iii) descrição da tecnologia de filtragem de Prony e exemplos que demonstram as suas capacidades na prática. Usando exemplos simples, apresentamos ideias básicas da tecnologia, ilustrando os principais pontos que são importantes para a aplicação deste método no processamento de dados sísmicos reais. Os resultados obtidos mostram uma boa estabilidade do algoritmo para diferentes formas de onda e na presença de outros sinais e de ruído. Esperamos que esta abordagem chame a atenção de especialistas para o método não-linear de filtragem de Prony, bem como para aspectos de sua implementação em análise espectral de geofísica.

Palavras-chave: transformadas de Prony e Fourier, análise espectral, decomposição de sinal e filtragem.

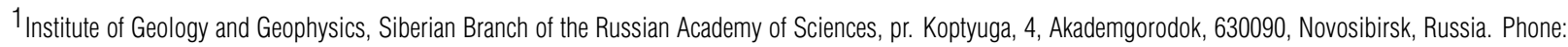
(73832) 333909 - E-mail: george@uiggm.nsc.ru

2Laboratory of Petroleum Engineering and Exploration, State University of Norte Fluminense Darcy Ribeiro, Rod. Amaral Peixoto, km 163, Av. Brennand, s/n, Imboassica, 27925-535 Macaé, RJ, Brazil. Phone: +55 (22) 2765-6562; Fax: +55 (22) 2765-6577 - E-mails: slava@lenep.uenf.br; slava211054@gmail.com
} 


\section{INTRODUCTION}

Fourier Transform (FT) and its discrete form are well-known and widely used in spectral analysis with standard seismic data processing. It is computationally efficient and easy to implement. As a rule, these procedures give good results in the analysis of spectral contents of long-time data. However, there are some drawbacks, which limit its application in the case of short-time signals (for example, reflections from the target horizons). One of the most prominent manifestations of this limitation is its inability to resolve high DFT frequencies. The frequency resolution or the spectral resolution is determined by the minimum difference in hertz between the two harmonics with different frequencies, which are estimated by computing the spectrum for the sum of these harmonics (Marple, 1989).

Frequency resolution of the DFT is entirely defined by the length of a window or the data limitation, i.e., to gain a greater frequency resolution requires a longer period of observation for the data. Another important drawback of the DFT is the impact of side wiggles (the Gibbs Phenomenon), see Bath (1974). There are also other limitations such as interference with different signals and noise in the time domain. It changes shape of the signal and influences properties of the DFT, which will undoubtedly limit the frequency resolution as well as the accuracy in calculating the amplitude and phase. In addition, it is known that the DFT can create false components in the calculated spectrum, which could interfere with definition of desired frequency components (Hamming, 1989). Other losses in terms of noise, resolution and stability are necessary to analyze during the use of DFT for spectral analysis of short signals.

Thus, these considerations limit applications of such transformations. In our opinion, the basis of these restrictions is the discrepancy between short duration of pulses and the endless functions (sine and cosine) used in FT. This is the basis of various emerging problems in the traditional spectral analysis of shorttime functions.

Comprehensive studies of digital spectral estimation have led to a significant development of advanced technologies during the past few decades (Marple, 1989; Marks, 2009). For example, it led to a technology based on wavelet analysis which provides better results for the short-time signals (Chui, 1992). However, use of such techniques in seismic data processing may have some limitations in terms of formal selection of orthogonal functions such as basis of the corresponding transform.

Alternative way is to use Prony analysis (PA). The Prony method is based on functions that are better suited for the nature of real seismic impulses. Description of data using sum of complex exponential (Prony decomposition), was suggested by the French engineer and mathematician Gaspard Riche (Baron de Prony) more than two centuries ago (de Prony, 1795). Although this method is a generalization of the Fourier method, it was forgotten until 1960s. Compared with other methods of analysis of oscillating signals, such as the Fourier analysis, the PA method describes uniformly sampled real data as a linear combination of exponentially damped cosines. It has the following basic properties:

- PA is a parametric estimation;

- PA requires uniformly sampled data;

- PA describes observed signal as a sum of exponentially decaying oscillating functions;

The main advantages of the PA method can be summarized as:

- It is designed to operate with significantly shorter data, while maintaining high-frequency resolution;

- It typically provides greater accuracy in estimating the frequency values than when using the DFT with the same duration of the window;

- It does not have a problem of leaked spectral components;

- It can calculate four parameters: amplitude, frequency, phase and attenuation (damping factor) for the approximated signals.

Renewed research interest in the Prony method can be attributed to the development of more powerful computers and the need to provide good spectral resolution in the processing of data in various fields of science and technology, in which the shape of the observed signals is close to a decaying sinusoid. At the same time new schemes for the Prony decomposition were also developed (see, e.g., Osborne, 1975; Kumaresan, 1983; Marple, 1987; Osborne \& Smyth, 1991, 1995; Beylkin \& Monzón, 2005; Bracale et al., 2007). Some of these schemes are based on the least-squares method, nonlinear optimization or polynomial factorization. These schemes are directly related to the analysis of autoregressive models (AR-models) and have high speed operations. Other schemes use singular value decomposition method (SVD), which provides good results for a relatively high signalto-noise ratio (SNR) of data (greater than 2). However, in the case of extremely low SNR or the rapid decay of the observed signal, results obtained by the SVD method are unsatisfactory. It is due to considerable difficulties in separating the singular values. Some aspects of stable estimation for noisy data and 
comparison with the properties of wavelet decomposition can be found in Berti et al. (2007) and Lobos et al. (2009). Overview of the problem of estimating parameters of approximation of exponential sums for experimental data can be found in Marple (1987), Kahn et al. (1992), Holmström \& Petersson (2002), and Potts \& Tasche (2009).

Paper by Kovaljev \& Telepnev (1981) is one of the first works on the application of Prony method and AR-models to processing and interpretation of seismic data (see also Kovaljev et al. (1992), Mitrofanov et al. (1993)). They showed that the use of damping factor as one of the parameters of Prony decomposition provides more accurate and detailed forecast of deep and lateral variations in reservoir properties, in particular, the anomalies of high pressure (see also Helle et al., 1993).

Further development introduced new method of seismic data processing called Prony filtration method. The method provides stable estimate of damped sinusoidal components of short signals and uses part of these components to build image of the analyzed seismic impulses. Therefore, the Prony filtration results are presented in the form of traditional time sections (Mitrofanov et al., 1998b). Usually, two parameters of Prony, the frequency and damping, are the basis for selection of damped sinusoidal components. As a result, the image of seismic traces helps to improve resolution of short seismic signals and to identify areas with anomalous values of scattering (dispersion). Testing of these algorithms was performed on a large number of mathematical and physical models (Mitrofanov et al., 1998a, 1999, 2003a). Tests had confirmed effectiveness of this approach in analyzing the reservoir structure, contouring of oil/gas production areas, as well as in determining the productive reservoir properties. In some sense, it should be expected, taking into account that seismic signals are similar to a damped sinusoid, and the damping coefficients are associated with the $Q$ factor, playing a significant role in the description of lithology, fluid content and pressure variations. For recent results on Prony filtration use for a transient impulses analysis and non-stationary components detection (Ribeiro et al., 2003).

The following is a list of problems in which the Prony filtration method was successfully used (Mitrofanov et al., 2001, 2003b, 2005; Mitrofanov \& Priimenko, 2007).

\section{- Seismic problems:}

1. Frequency analysis of the medium response. In this case, based on some heuristic ideas and hypotheses, various properties of the medium can be determined. For instance, the allocation of consolidated and not consolidated parts of the medium is determined by analyzing high-frequency response.

2. Studying local elements of horizons. For example, small faults, zones of wedge-shaped or pinch-out of the target horizons may be better studied by analyzing highfrequency components of the recorded signals.

\section{- Geological problems:}

1. Analysis of the conditions of reservoir. For example, quality of the caprock or possibility of stratigraphic trap can be analyzed;

2. Mapping reservoir in time and/or spatial domains.

\section{- Field development problems:}

1. Forecasting points and/or areas with high productive properties, such as in the case of test drilling;

2. Evaluating the properties of productive horizons, for example, the conditions of oil/gas accumulation;

3. Defining relations between the Prony parameters and logparameters associated with productive horizons.

The article is organized as follows. In section "PRONY METHOD" we discuss the classical method of Prony, describing its main shortcomings and possible ways to overcome that. Special attention is paid to the signals that are similar to seismic transient impulses. In section "PRONY FILTRATION" we discuss use of the discrete Prony spectrum for selection of damped components. We analyse influence of Prony filtration procedures on the shape of the signal form and the process of selection of the target impulses from the other ones, including noise. In section "PRONY FILTRATION METHOD" we describe main elements of this method and their application in the processing of real seismic data.

\section{PRONY METHOD}

The original Prony method seeks to fit a deterministic exponential model to equally spaced data points. It was discussed in details by Marple (1987) and Therrien (1992). A brief review of this technique is given here.

Assuming a signal data $x[n]$ with $N$ complex samples $x[1], x[2], \ldots, x[N]$. The Prony method will fit the data, for example, the seismic trace, with the sum of $M$ complex exponential functions

$$
y[n]=\sum_{k=1}^{N} A_{k} \cdot e^{(n-1)\left(\alpha_{k}+j 2 \pi f_{k}\right) \cdot T_{0}+j \theta_{k}}
$$


for $n=1,2, \ldots, N$, where $j^{2}=-1$ and $T_{0}$ is the sampling time interval. The objective is estimation of amplitudes of the complex exponential $A_{k}$, damping factors $\alpha_{k}$, harmonic frequencies $f_{k}$ and phases $\theta_{k}$. If these parameters are determined correctly, then the original signal fits with a high degree of accuracy.

The discrete signal can be expressed in the form

$$
y[n]=\sum_{k=1}^{M} h_{k} z_{k}^{n-1}
$$

where $h_{k}=A_{k} \cdot e^{j \theta_{k}}$ and $z_{k}=e^{\left(\alpha_{k}+j 2 \pi f_{k}\right) \cdot T_{0}}$ are complex parameters

The fitting of a designated signal is usually accomplished by minimizing the total squared error over the $N$ data values (Marple, 1987):

$$
\delta=\sum_{n=1}^{N}(\varepsilon[n])^{2}
$$

where

$$
\varepsilon[n]=x[n]-y[n]=x[n]-\sum_{k=1}^{M} h_{k} z_{k}^{n-1}
$$

represents the complex error between the original data samples $x[n]$ and the linear approximation $y[n]$. This turns out to be a difficult nonlinear problem, which can be solved by the classical Prony method. If as many data samples are used as there are exponential parameters, then an exact exponential fit to the data may be made.

Consider the $M$-exponent discrete function:

$$
x[n]=\sum_{k=1}^{M} h_{k} z_{k}^{n-1}
$$

The $M$ equations of (5) may be expressed in matrix form as:

$$
\begin{gathered}
\left(\begin{array}{cccc}
z_{1}^{0} & z_{2}^{0} & \cdots & z_{M}^{0} \\
z_{1}^{1} & z_{2}^{1} & \ldots & z_{M}^{1} \\
\vdots & \vdots & \vdots & \vdots \\
z_{1}^{M-1} & z_{2}^{M-1} & \ldots & z_{M}^{M-1}
\end{array}\right) \\
\times\left(\begin{array}{c}
h_{1} \\
h_{2} \\
\vdots \\
h_{M}
\end{array}\right)=\left(\begin{array}{c}
x[1] \\
x[2] \\
\vdots \\
x[M]
\end{array}\right)
\end{gathered}
$$

Observe that in Eq. (6) (viewing as a linear system in $h_{k}$ ) we have the Vandermonde matrix. It is well-known that the Vandermonde matrix can be associated with an interpolation polynomial. Prony proposed to define the polynomial that has the $z_{k}$ exponents as its roots:

$$
\begin{aligned}
F(z) & =\prod_{k=1}^{M}\left(z-z_{k}\right) \\
& =\left(z-z_{1}\right)\left(z-z_{2}\right) \cdots\left(z-z_{M}\right)
\end{aligned}
$$

Eq. (7) may be represented as the sum:

$$
\begin{aligned}
F(z) & =\sum_{m=0}^{M} a[m] z^{M-m} \\
& =a[0] z^{M}+a[1] z^{M-1}+\cdots+a[M]
\end{aligned}
$$

with complex coefficients $a[m]$, such that $a[0]=1$. Shifting index in Eq. (5) from $n$ to $n-m$ and multiplying by the parameter $a[m]$ we get:

$$
a[m] x[n-m]=a[m] \sum_{k=1}^{M} h_{k} z_{k}^{n-m-1}
$$

Eq. (9) can be modified into:

$$
\begin{gathered}
\sum_{m=0}^{M} a[m] x[n-m] \\
=\sum_{k=1}^{M} h_{k} z_{k}^{n-M}\left(\sum_{m=0}^{M} a[m] z_{k}^{M-m-1}\right)
\end{gathered}
$$

The right-hand internal summation in Eq. (10) may be recognized as polynomial defined by Eq. (8), evaluated at each of its roots $z_{k}$ yielding the zero result:

$$
\sum_{m=0}^{M} a[m] x[n-m]=0
$$

Eq. (11) is a linear difference equation, with the homogeneous solution represented by Eq. (5).

The $M$ equations, representing the exact values of $a[\mathrm{~m}]$ satisfied to Eq. (10), can be represented as an $M \times M$-matrix 
equation:

$$
\begin{gathered}
\left(\begin{array}{cccc}
x[M] & x[M-1] & \cdots & x[1] \\
x[M+1] & x[M] & \cdots & x[2] \\
\vdots & \vdots & \vdots & \vdots \\
x[2 M-1] & x[2 M-2] & \cdots & x[M]
\end{array}\right) \\
\times\left(\begin{array}{c}
a[1] \\
a[2] \\
\vdots \\
a[M]
\end{array}\right)=-\left(\begin{array}{c}
x[M+1] \\
x[M+2] \\
\vdots \\
x[2 M]
\end{array}\right)
\end{gathered}
$$

Note that in Eq. (12) (viewing as a linear system in $a[m]$ ) we have the Toeplitz matrix. Using Eq. (12) we can separate the set of parameters $h_{k}$ from one of $z_{k}$.

Thus, to find coefficients and exponential parameters of Eq. (1), the Prony method can be implemented in three steps:

1. Solve Eq. (12) to find coefficients of $F(z)$.

2. Solve equation $F(z)=0$, defined by Eq. (8), to find the roots $z_{1}, z_{2}, \ldots, z_{M}$. So the damping factor and frequency are

$$
\begin{aligned}
\alpha_{k} & =\ln \left|z_{k}\right| / T_{0}, \\
f_{k} & =\left(2 \pi T_{0}\right)^{-1} \operatorname{arctg}\left(\operatorname{Im}\left\{z_{k}\right\} / \operatorname{Re}\left\{z_{k}\right\}\right)
\end{aligned}
$$

3. Solve Eq. (5). For known $\alpha_{k}, f_{k}$ this system is linear. So the amplitude and phase are

$$
A_{k}=\left|h_{k}\right|, \theta_{k}=\operatorname{arctg}\left(\operatorname{Im}\left\{h_{k}\right\} / \operatorname{Re}\left\{h_{k}\right\}\right)
$$

Therefore, original Prony algorithm reduces complex problem of nonlinear fit to the trivial and computational inexpensive tasks of (i) solving linear systems of equations and (ii) finding the roots of a polynomial.

In most cases, there are more data points than exponential parameters: $N>2 M$. In this case, Eq. (12) is modified to

$$
\begin{array}{r}
\left(\begin{array}{cccc}
x[M] & x[M-1] & \cdots & x[1] \\
x[M+1] & x[M] & \cdots & x[2] \\
\vdots & \vdots & \vdots & \vdots \\
x[N-1] & x[N-2] & \cdots & x[N-M]
\end{array}\right) \\
\times\left(\begin{array}{c}
a[1] \\
a[2] \\
\vdots \\
a[M]
\end{array}\right)=-\left(\begin{array}{c}
x[M+1] \\
x[M+2] \\
\vdots \\
x[N]
\end{array}\right)
\end{array}
$$

We can re-write this as an $(N-M) \times M$-matrix equation

$$
\mathbf{X a}=-\mathbf{x},
$$

which can be solved in the least-squares sense

$$
\mathbf{a}=-\left(\mathbf{X}^{H} \mathbf{X}\right)^{-1} \mathbf{X}^{H} \mathbf{x},
$$

where superscript $H$ denotes Hermitian transpose: $\mathbf{X}^{H}=\overline{\mathbf{X}}^{*}$. Details of implementation of this "least-squares Prony method" can be found in Marple (1987) and Osborne \& Smyth (1995).

Each exponent, used in Eq. (1), is determined by four real parameters: amplitude, frequency, attenuation (damping) and phase. Number of such exponents, sampling interval $T_{0}$ and number of data samples $N$ (or total time interval $T \equiv(N-$ 1) $T_{0}$ ) also play an important role. As it will be shown later, the position of analyzed interval (denoted by $\tau$ ) in the full set of observed data is also important.

By analogy with the discrete Fourier spectrum, we can consider a set of four parameters, corresponding to individual exponents, as a discrete Prony spectrum, i.e.,

$$
\Re_{\tau, T}(M)=\left\{A_{k}, \alpha_{k}, f_{k}, \theta_{k}\right\}_{k=1}^{k=M}
$$

The Fourier spectrum is a set of parameters: amplitude, phase and the third parameter is a fixed frequency. The Prony spectrum is a set of four parameters. There is an important difference between the Fourier and Prony transforms. Unlike the DFT, where the frequency sampling is equal, the frequency in the case of the Prony transform can have arbitrary values and is one of the estimated parameters. So, in the case of discrete Prony spectrum we will have an irregular frequency range for each signal. As a result, for some bands of frequencies the values of the Prony parameters are absent and the width of these bands may be very different depending on the selected data.

The transition of observed continuous data, for instance, seismic traces, to the discrete Prony spectrum can be represented as follows:

$$
\begin{aligned}
x(t) & \stackrel{\text { sampling of data by } T_{0}}{\Longrightarrow}\{x[i]\} \\
\text { transient selection by } \tau \text { and } T & \Longrightarrow \\
& \stackrel{\Longrightarrow}{\Longrightarrow} \stackrel{\text { Prony transform }}{\Longrightarrow} \Re_{\tau, T}(M)
\end{aligned}
$$

Here $\{x[i]\}_{i=1}^{i=I}$ is the total set of discrete data and $\{x[n]\}_{n=1}^{n=N}, N \leq I$, is part of the data used for the Prony transform, i.e., $\{x[n]\}_{n=1}^{n=N} \subseteq\{x[i]\}_{i=1}^{i=I}$. The discrete Prony spectrum $\Re_{\tau, T}(M)$ depends on the parameters data selection $\tau, T$, and the order of approximation $M$. 
The scheme (19) will serve as the basis for all our subsequent constructions. Before applying it, we must make some comments. For real data samples we have pairs of complex conjugate exponentials (Marple, 1987). Therefore, such data are decomposed by means of damped sinusoids rather than through the complex exponentials. If we use this model for an approximation of samples, the number of components $M$ is always even and in this case the decomposition will have $L=M / 2$ damped sinusoids. It is obvious that in the seismic data processing we usually are in the framework of this concept. Then, for the real data case Eq. (1) is rewritten in the form of damped sinusoids:

$$
y[n]=\sum_{k=1}^{L} A_{k} \mathrm{e}^{\alpha_{k}(n-1) T_{0}} \cos \left(2 \pi f_{k}(n-1) T_{0}+\theta_{k}\right)
$$

The classical Prony method may be formulated in various ways. Some of these approaches were discussed in the introduction. The most important thing is that we can describe observed seismic data in the form of Eq. (20) and estimate the number of damped sinusoids and their parameters.

Although the real seismic signals are similar to the exponential sinusoid (Prony components), there are still some differences. In our research we analyzed a lot of discrete Prony spectra for various short-time seismic signals obtained by mathematical and physical modelling, as well as in real experiments.

Typically, for an acceptable approximation of the wavelet, we can limit ourselves to three or four pairs of complex harmonics (Figs. 6 and 7), i.e., $M \leq 8$. But sometimes for a more complete fitting we need to use up to 10 or 11 pairs of harmonics. In this case, there are two interesting features. First, the wider the signal is in time domain, the lesser number of harmonics we need. This fact is confirmed by comparing the Prony spectra for signals presented in Figures 1 and 2. Secondly, the higher the decay of the observed signal, the wider the spread in the Prony parameter values into 4D space. For example, Ricker's wavelet is one of the pulses with a broad spectrum. Figure 2 shows the Ricker pulse with the predominant frequency $40 \mathrm{~Hz}$, which is well approximated by eight Prony components, i.e., $M=16$. Notably, the frequencies of corresponding components have a large spread (from $15 \mathrm{~Hz}$ up to $100 \mathrm{~Hz}$ ). In addition, there are several large variations in the values of the amplitude and phase parameters.

Currently, many software tools have a common procedure for the Prony transform, which could be used for the analysis of real signals. However, in the case of real data, there are several important features that complicate its analysis and processing:
1. Signal position is not known with sufficient accuracy;

2. Real seismic impulse is often a short-time (20-30 samples);

3. Usually, for target objects, a few of reflected signals with different features are available in the analyzed time interval;

4. For real seismic data the spectrum of noise can be close to that of the evaluated signal.

Some of these properties are illustrated in Figures 3-5, which represent a damped sinusoid with a time delay, localized in the interval $(0.092 \mathrm{~s}, 0.206 \mathrm{~s})$. When exact arrival time of the signal is known, we can determine appropriate Prony decomposition parameters, i.e., $\Re_{\tau, T}(M)$, without any problems, and have a good approximation to the signal, represented by the black line in part (a) of all figures. In this case, the Prony components have different parameters, but the fourth component has the parameters that correspond to the true ones with high accuracy, see part (b). These parameters can be simply selected from a common set of values of the spectrum through an analysis of two parameters: the frequency and damping (Fig. 3(C)). In this case we can guarantee a very good approximation of the signal (Fig. 3(d)).

When there is a small error in the arrival time of the signal (only one sample), the result is not so good (Fig. 4(a)). However, after the Prony parameters selection, we can again obtain a good approximation of the waveform (Fig. 4(d)). But, a bigger error in the arrival time of signals (two samples) does not give such a result (Fig. 5). Also we have incorrect Prony parameters in this case.

So, we have the first problem for seismic impulses: stable and well-defined parameters of Prony decomposition when their arrival times are not precisely defined. In this case, various algorithms give different results depending on the shape of the seismic signal and values of the SNR.

The second problem is related to Prony estimation of parameters for the full traces. In this case, we need to combine different Prony spectra corresponding to different time intervals.

The latter is complicated by the fact that in a real seismic experiment, we do not have enough information about the location of each of the analyzed signals. Therefore, we must evaluate and analyse the Prony parameters for various time intervals, i.e., need to find the optimal sampling interval as well as $\tau$ and $T$ (see, e.g., Lee \& Kim, 2005; Bracale et al., 2007). This step was an important element in creating algorithms of Prony filtration, capable of working with real seismic data. This problem is not covered in traditional papers. 

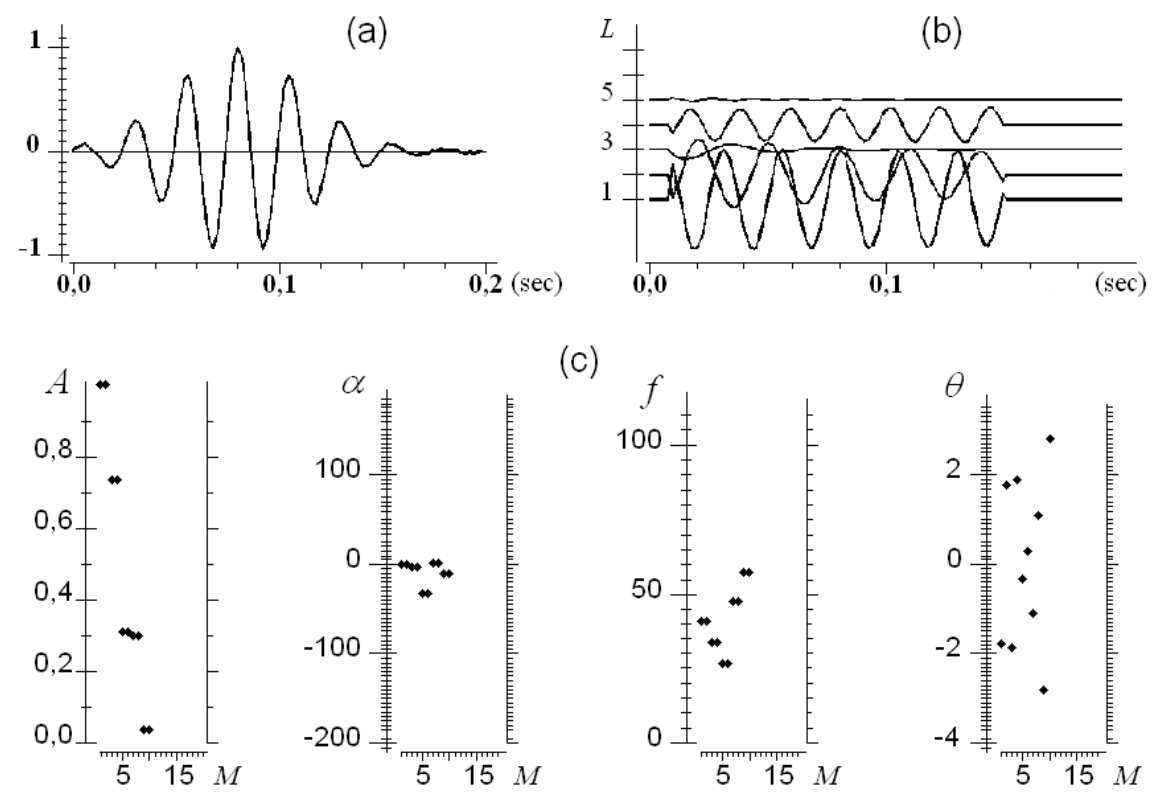

(c)
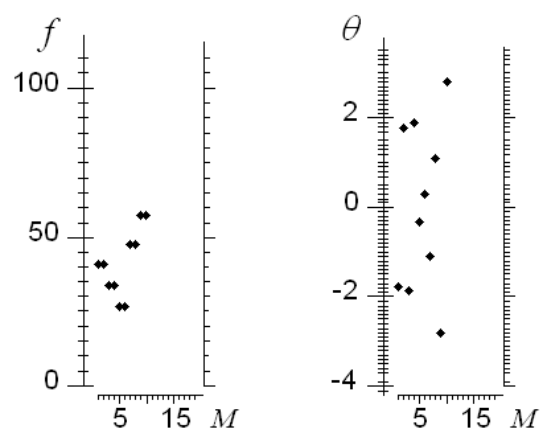

Figure 1 - Signal with smooth decay: (a) - signal, (b) - Prony components, (c) - values of the discrete Prony spectrum.
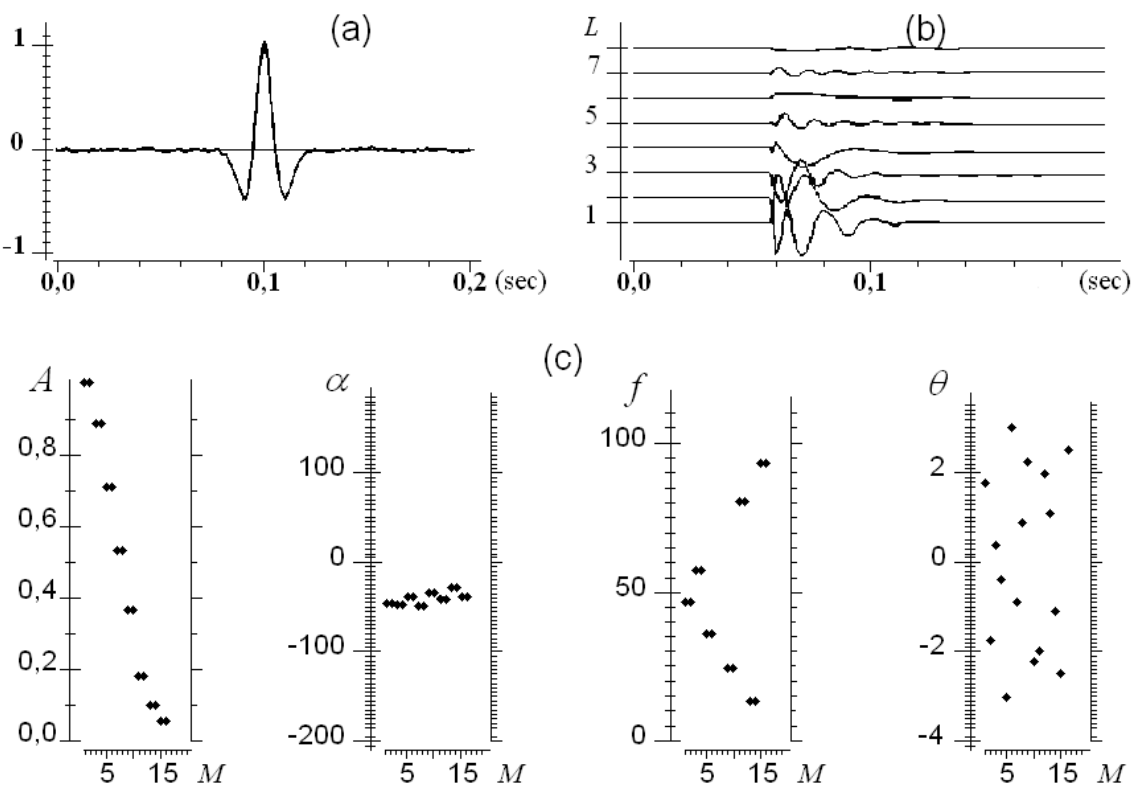

(c)
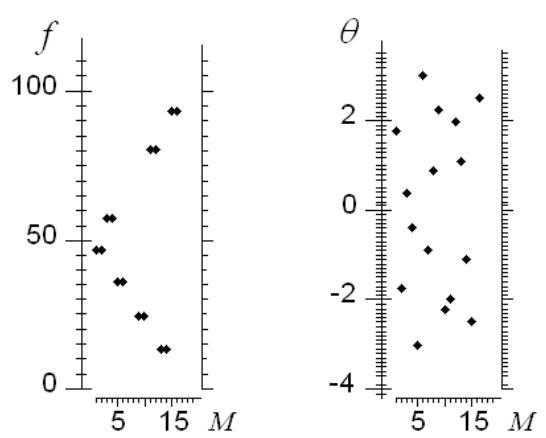

Figure 2 - Ricker's wavelet: (a) - wavelet, (b) - Prony components, (c) - values of the discrete Prony spectrum.

\section{PRONY FILTRATION}

To understand use of the discrete Prony spectrum in the selection of impulse components, i.e., in the process of Prony filtration, consider a few simple examples. The selection procedure can be used to separate any of the individual components or a certain part of them for the observed wave field approximation, which will be used for further interpretation. This selection de- pends on the seismic/geological tasks and features of the Prony transform. First of all, we need to solve, except for two problems stated above, the following third problem: how to choose optimal parameters for the Prony decomposition, ensuring its best result. As an illustration, consider two examples of the Prony spectrum, using signals in the form of decaying sinusoids (Figs. 6 and 7). The initial signal form is shown in red. In both examples, the Prony decomposition was performed using a moving time 


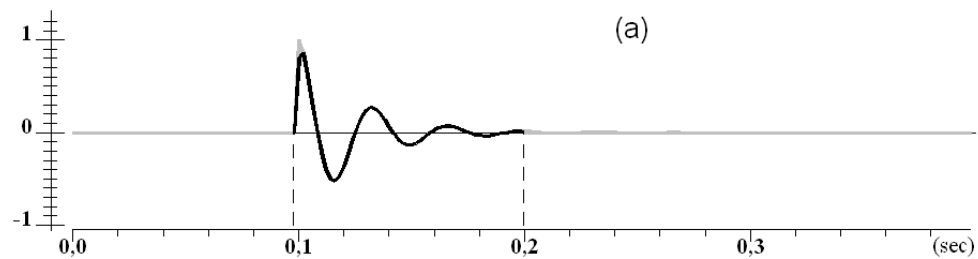

(c)
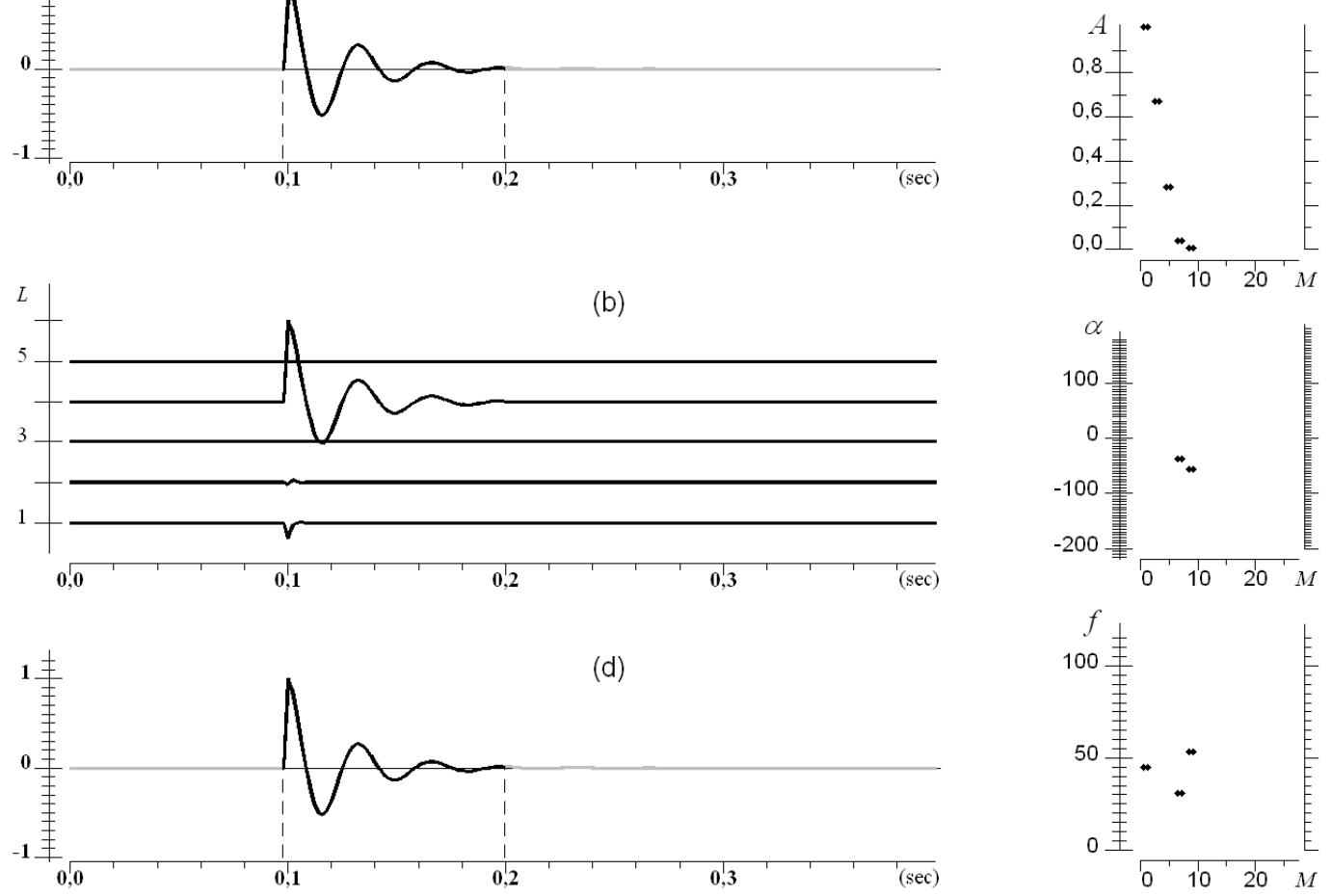

Figure 3 - Signal form fitting, case of the exact arrival time

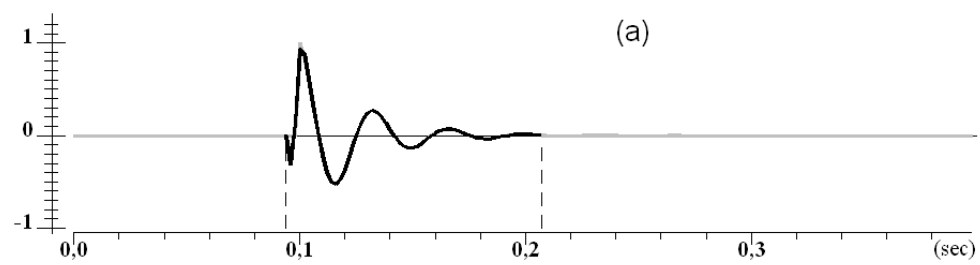

(c)
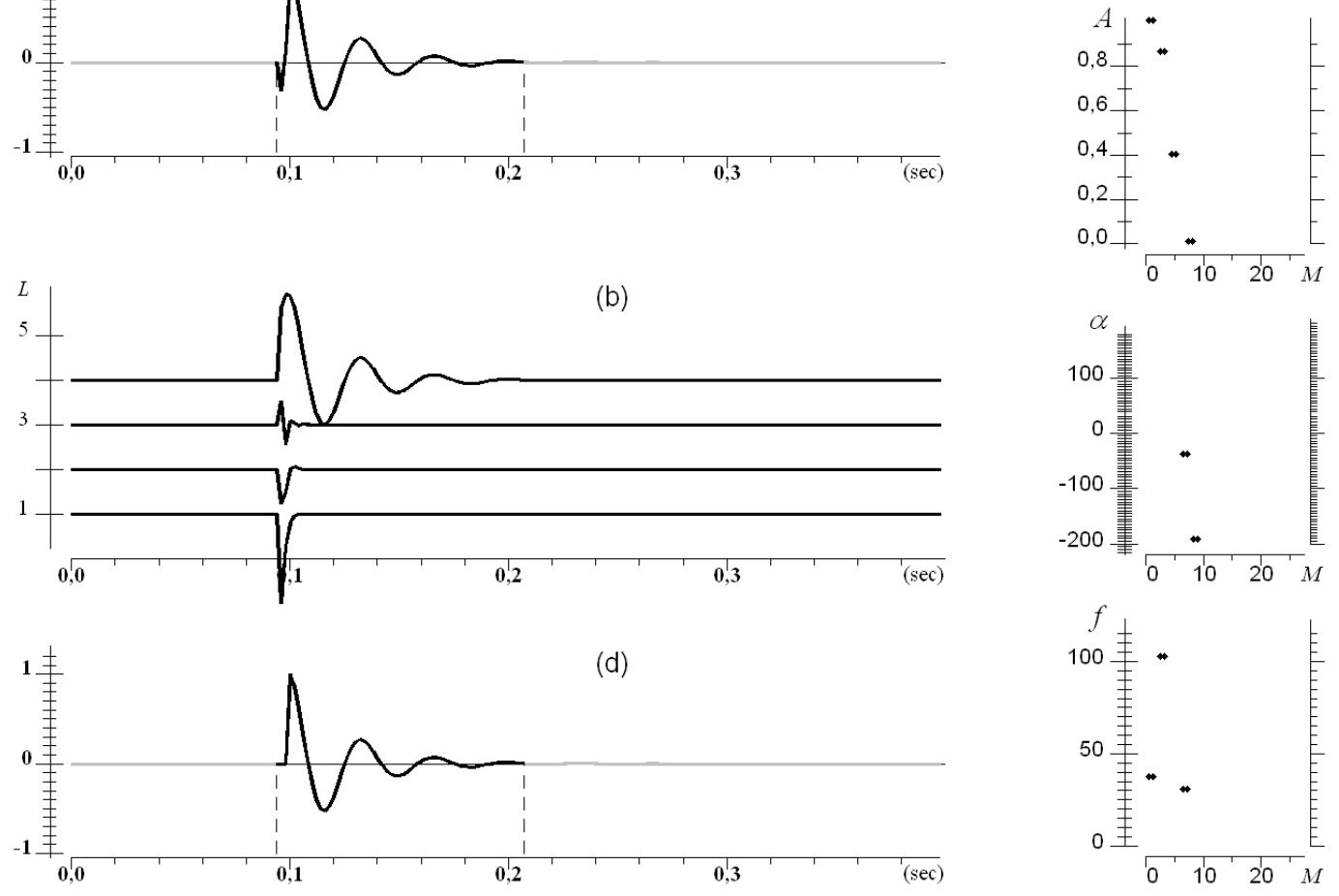

Figure 4 - Signal form fitting, case of $2 \mathrm{~ms}$ error (one sample) in the arrival time. 


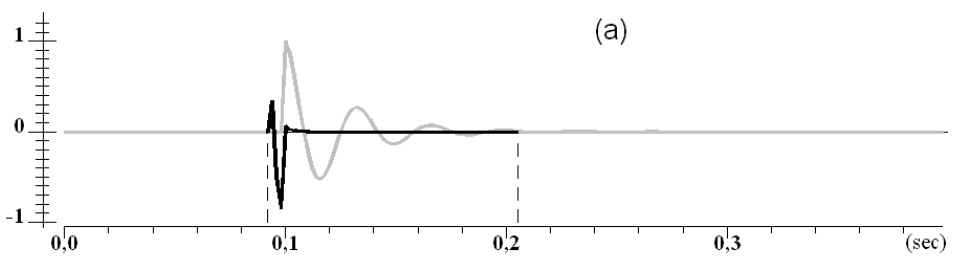

(c)
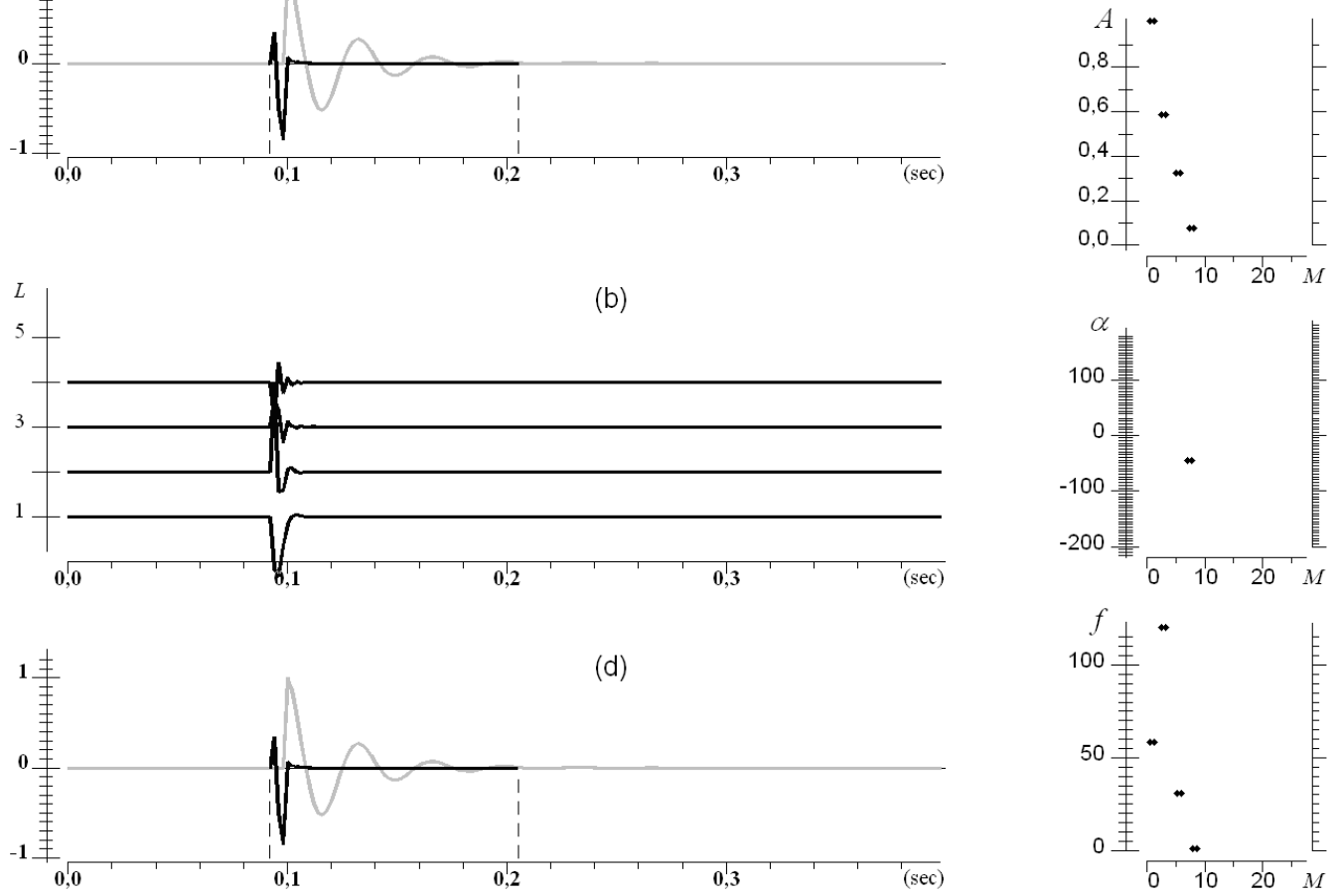

Figure $\mathbf{5}$ - Signal form fitting, case of $4 \mathrm{~ms}$ error (two samples) in the arrival time.

interval (window) in the estimation of the spectrum. This determination of the Prony parameters is similar to the real data processing when we do not know exact location of the impulses. In the first example the length of moving time window was equal to 0.15 s (Fig. 6), while in the second example it was equal to $0.094 \mathrm{~s}$ (Fig. 7). In both cases fit to the test signal is poor (Figs. 6(a) and 7(a)). In addition, the combined Prony spectrum, when the spectra of all moving intervals are present, is quite complex (Figs. 6(c) and 7(c)). This leads to the complex structure of the combined Prony components that does not contain direct information about the original signal (Figs. 6(b) and 7(b)). Such properties are associated with limited information about the signal including its time arrival, and as a result, we cannot accurately identify the signal and the Prony parameters (or components).

Furthermore, as it was noted above, the discrete Prony spectrum of observed data may have a rather broad set of parameters than damped sine wave. This makes it difficult to identify seismic impulses in the process of their separation in the analysis of real seismic data. Therefore, it was necessary to set up special procedures for determining the Prony parameters. The procedures are based on algorithms that guarantee stability of the Prony decomposition for different types of signals similar to real seismic ones. The general idea of the proposed special procedures is as follows: The discrete Prony spectra (18) obtained by separated short intervals using the least-square method (16) are joined for the total part of the processed record (detailed description of these procedures will be done in our next paper). This is done to minimize the difference between observed data and its approximated representation (19). Some examples of their application are given in Figures 6(d) and 7(d).

Figure 8 shows the results without (a) and with (b) special procedures. Again, it was assumed that the exact position of the signal was not known. Evidently, the general procedure for parameter estimation is not stable for signals with sharp entry. This is due to the nonlinear estimation of Prony parameters when such signals are located not far from the edge of the sample interval. Special procedures that modify the internal structure of Prony transformation and analyze the singular values of the corresponding matrices significantly improve the stability of the resulting estimates.

Special procedures are most important when we have a set of signals with different shapes. In this case we can have very unstable results. This often allows us to define specific characteristics for certain types of signals (Fig. 9). For example, comparing the middle parts of Figures 9(a) and 9(b) we can see, it is impossible to accurately detect the arrival time and signal forms in the first case. 


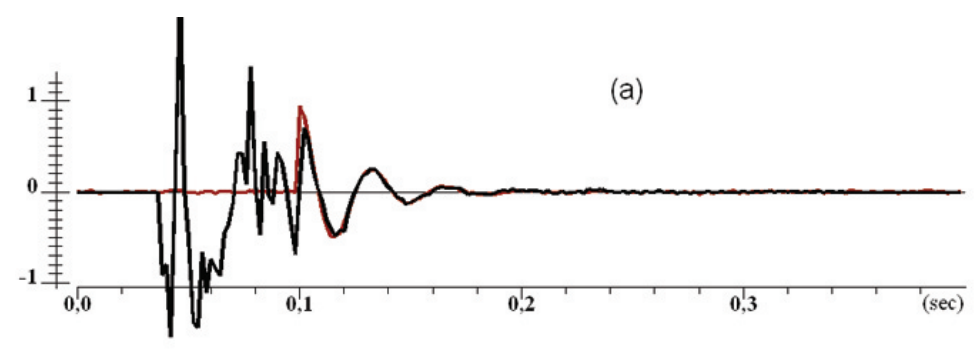

(c)
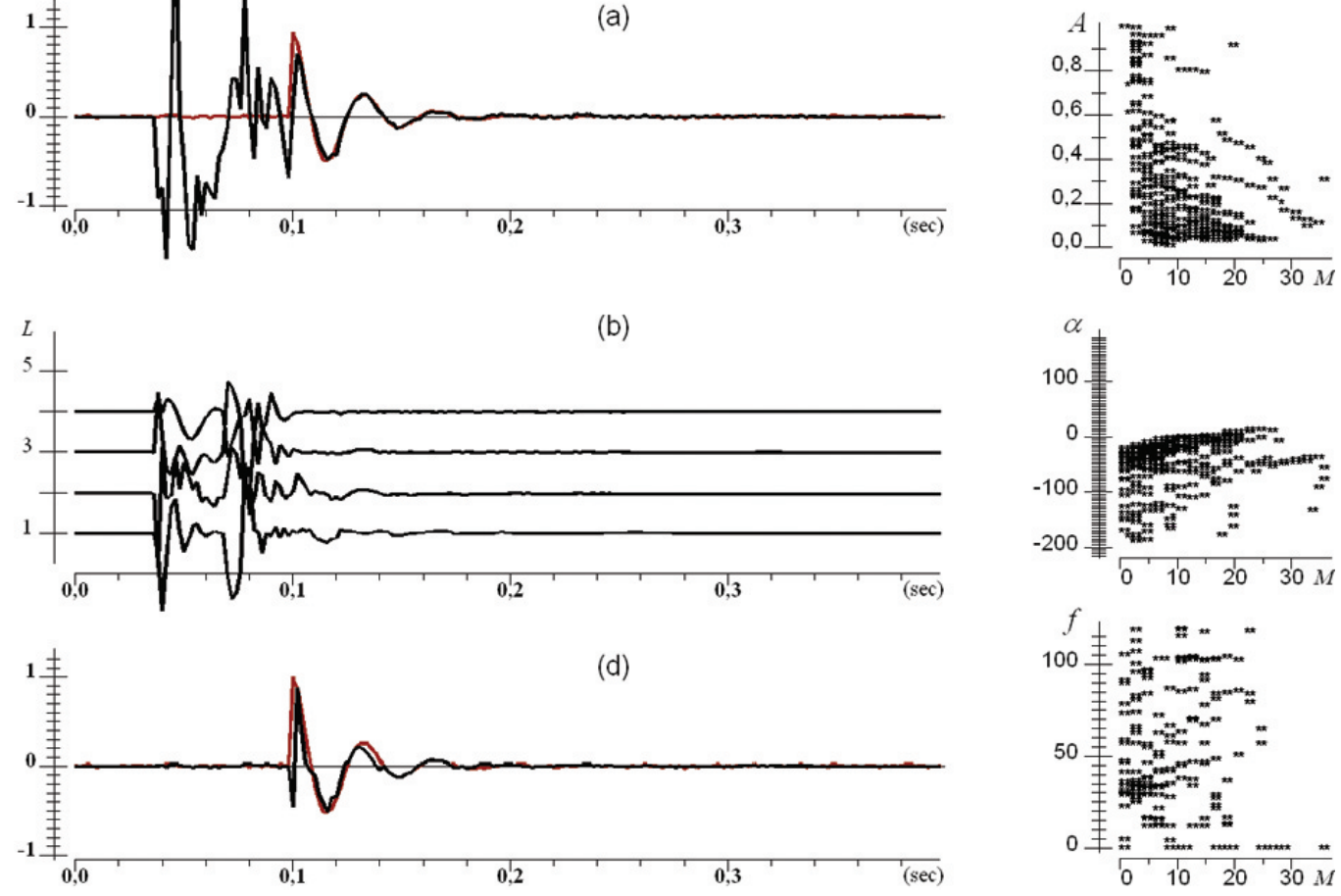

Figure 6 - Estimation of the Prony spectrum and pulse form using a moving short-time interval with duration of $0.15 \mathrm{~s}$. Result of approximation (a) based on the combined Prony components (b), the values of the Prony parameters (c): amplitude, attenuation, frequency; and the result of using special procedures (d).

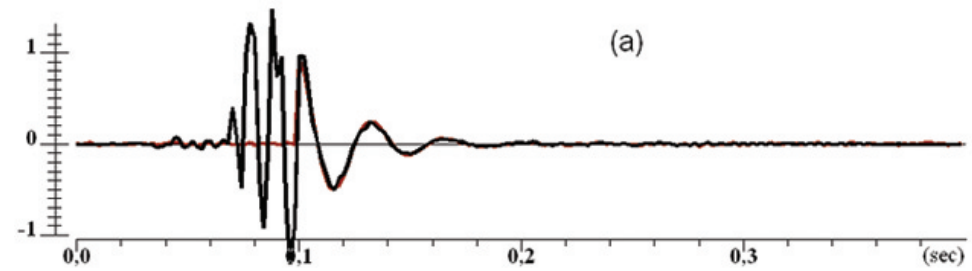

(c)
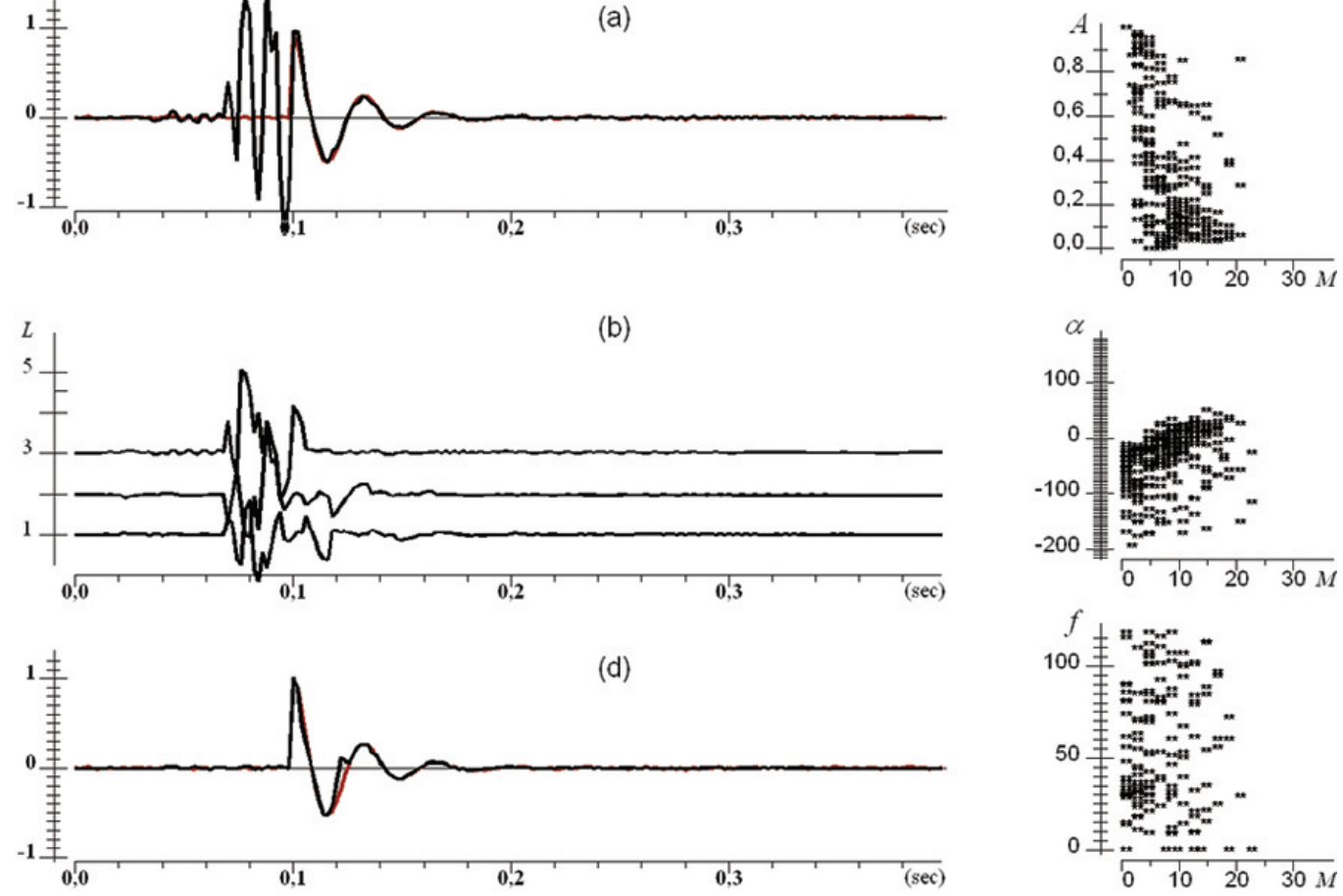

Figure 7 - Estimation of the Prony spectrum and signal form using a moving short-time interval with duration of 0.094s. Result of approximation (a) based on the combined Prony components (b), the values of the Prony parameters (c): amplitude, attenuation, frequency; and the result of using special procedures (d). 

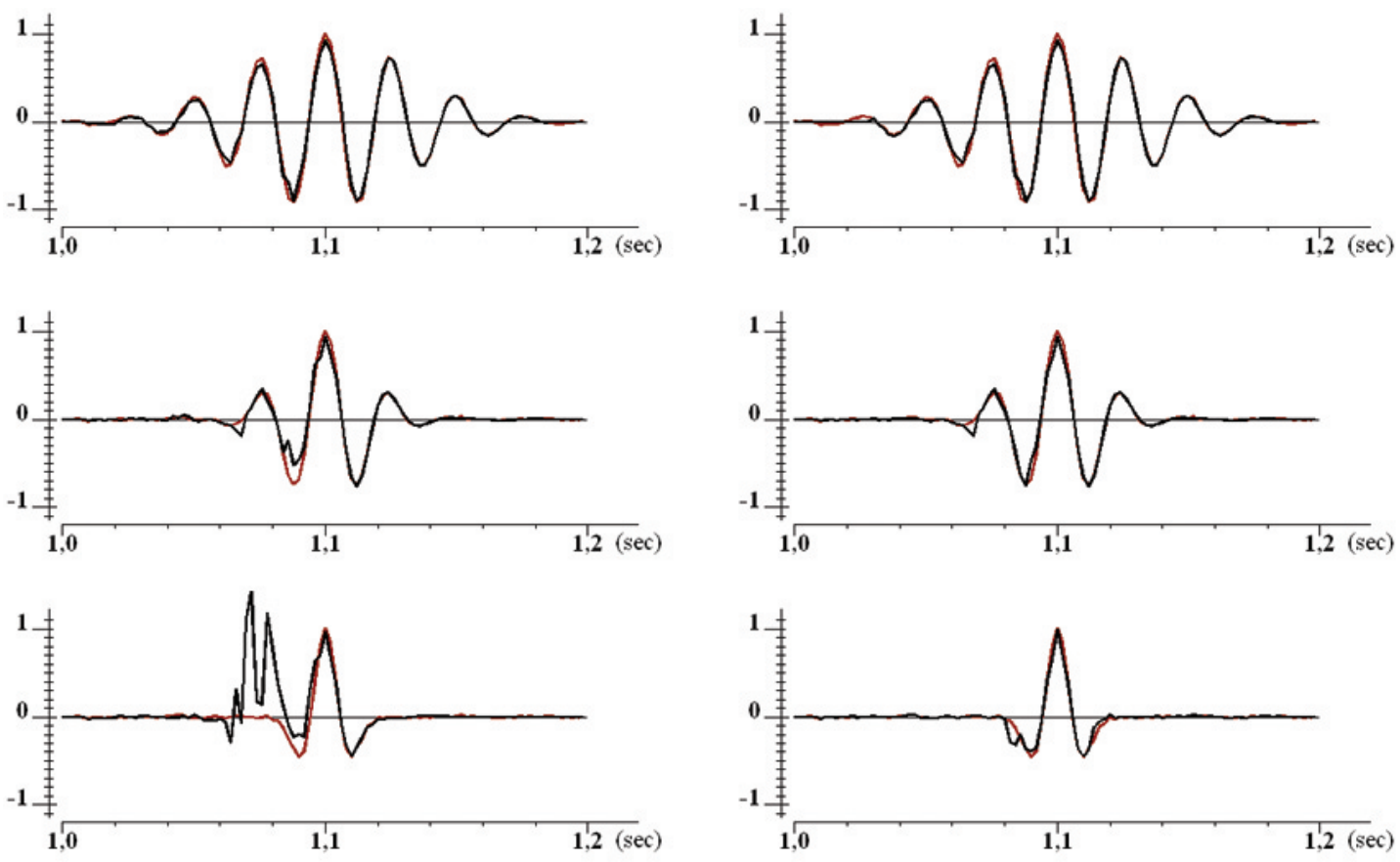

(a)

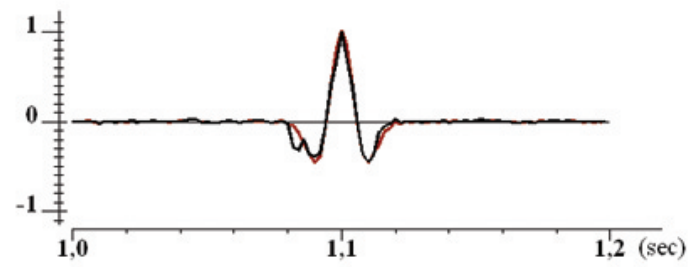

(b)

Figure 8 - Signal form fitting: (a) without and (b) with special procedures.
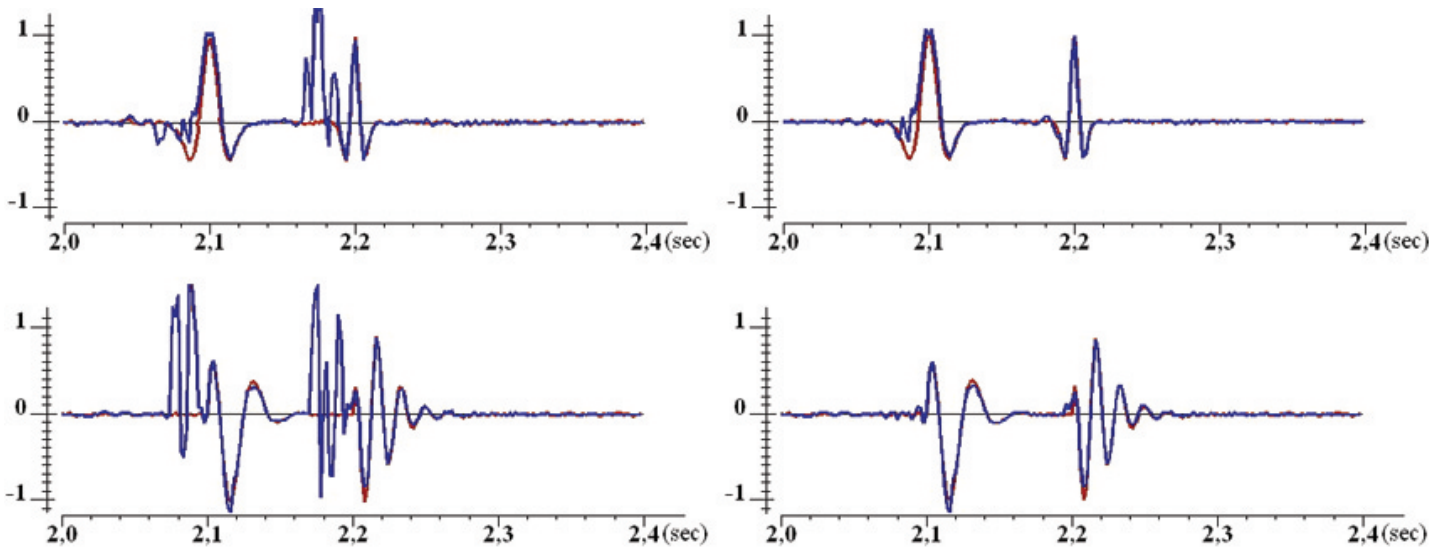

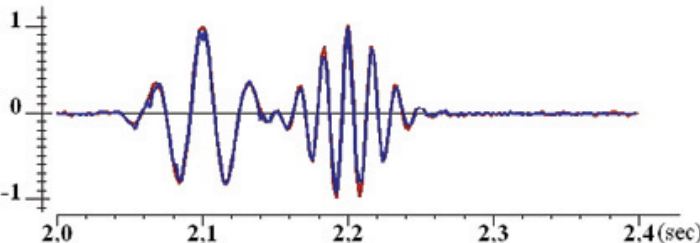

(a)

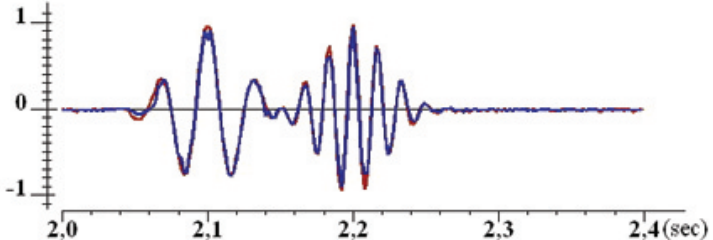

(b)

Figure 9 - Signal form fitting: (a) without and (b) with special procedures. 
Using such procedures allows us to provide good stability and an effective separation of signals in the time domain. Figure 10 shows results of simple experiments in the allocation of high-frequency $(80 \mathrm{~Hz})$ signal in the low-frequency $(40 \mathrm{~Hz})$. The aim of these experiments is the isolation of signal parameters differing from the mainstream. For all three cases presented, we got quite good results (black line). It should be noted that no prior information on the signal shape and its position was used. It reflects a real situation where the initial shape of the wavelet and the time of his arrival were not known. In addition, for the experimental data we had to be able to separate high-frequency components, which energy is several times less than that of the main (visible) components. In particular, in presented experiments the high-frequency signal was selected which amplitude was five times less than the amplitude of the fundamental signal.
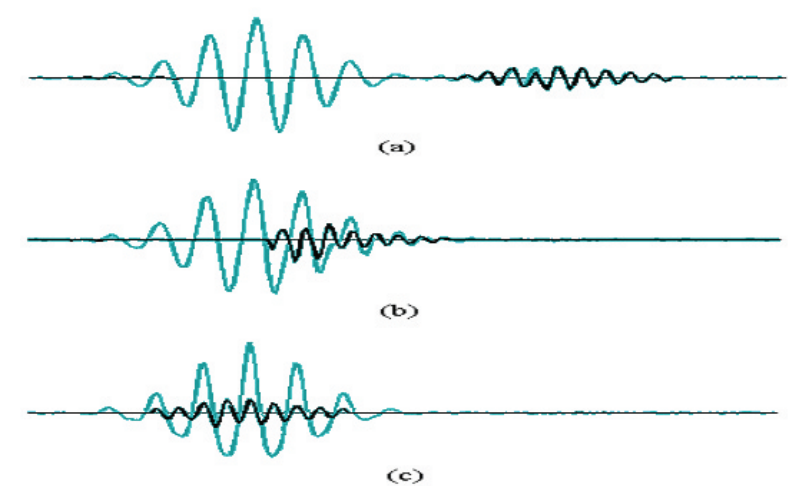

Figure $\mathbf{1 0}$ - Isolation of high-frequency component using the Prony filtration procedure.

Figure 10(a) shows the signals with a maximum distance. In Figures 10 (b) and 10(c) we observe the convergence of the arrival times of signals to their complete coincidence. The figures shows that regardless of its position, we could well determine the shape of the signals, and indicate with precision their position. The results show that the Prony filtering allows us to select the signal at different positions with good time resolution. Therefore, the use of Prony filtration for separation of high-frequency component creates a fairly good basis for the processing of real seismic data. However, it should be noted that this filtering can cause some distortion of the trace forms. As a rule, the greatest distortion is in the case of sharp entry of the signals. The strategy for determining the optimal parameters for the filtration was not used in these experiments. Use of such strategy will be discussed later.

There is another important aspect of the application of Prony filtration. Separation of individual components based on fixing the Prony parameters is interesting in itself, but in our opinion, the analysis of changes in the damping parameter as a function of frequency is even more interesting. This analysis can provide very important information about properties of the rocks.

Figure 11 shows some examples of such estimation for the synthetic signal, represented by an impulse in damped sinusoid form with frequency $f=20 \mathrm{~Hz}$ and the damping $\alpha=50$. Figure 11(a) shows the result of approximation of the signal Prony decomposition. Like the examples above, we did not use any information about location of the impulse. Application of our procedures allowed us to determine the full analyzed impulse accurately for any time. The initial signal is represented by red line, and its evaluation - blue. Figure 11(d) shows the complete set of parameters of Prony in this case. After selecting parameters, we succeeded in restoring the original waveform at the exact time and with the correct value of the damping parameter (Figs. 11(b) and $11(\mathrm{c}))$.

More complex synthetic signal is shown in Figure 12(a) (red line). In this case, we had three damped sinusoids along the trace with frequency $f=20 \mathrm{~Hz}$ and various values of the damping parameter $\alpha=50,75,100$, respectively, for the first, second and third sine wave.

Prony decomposition for this model, carried out in a moving short-time interval using our procedures, gave sufficient accuracy in the approximation of the full trace, see blue line in Figure 12(a). Note that more complex signal which is presented by three damped sinusoids leads to a full range of the Prony parameters (right panel of the figure) and to a greater variation of the damping parameter (down panel of Fig. 12(a)). The Prony filtration improves determination of the position of impulses and their shape (see blue line in Fig. 12(b)). As the result, the damping parameter is also better recovered (see bottom panel of Fig. 12(b)). In case of a moderate noise level the position of the impulses and their damping factors can be determined too (Fig. 12(c)).

\section{PRONY FILTRATION METHOD}

Let us discuss the main elements of this method. The Prony filtration method has several steps, which can be organized as follows:

1. Standard spectrum analysis to determine basic frequencies of the observed seismic data and the width of their spectrum. Components need to be identified in different parts of the frequency domain. This analysis is realized through separation of the most stable frequencies for all studied lines. Usually, it runs for a time interval greater than the duration of the impulse response reflected from the target object, and which may include reflected signals 

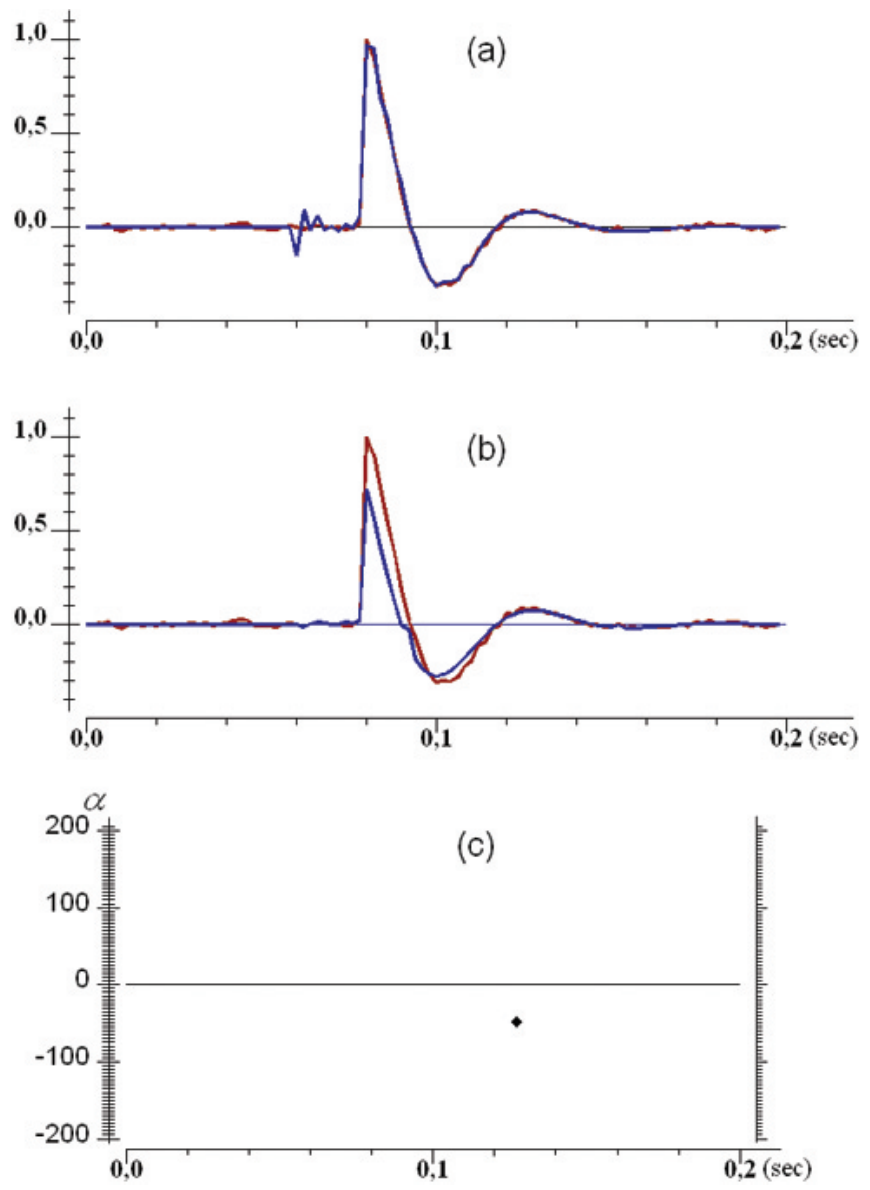

(d)
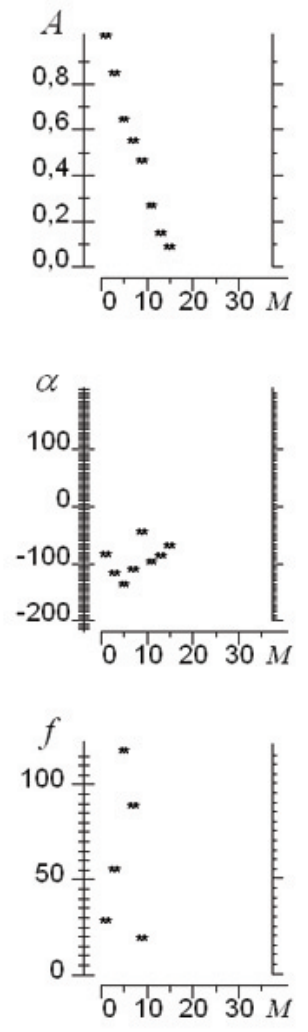

Figure 11 - Estimation of decaying component and its damping based on the Prony filtration procedure (see comments in the text).

from several seismic horizons. Thus, we have to understand that this is a component spectrum, corresponding to all these signals. As a result, a set of the basic and high frequencies will be prepared for the next step.

\section{Selection of parameters for the optimum Prony filtration,} depending on the task to be solved. The second step is very important for determining the Prony dynamic parameters and their use in solving the problem. This stage is the most complex and important in the method, which determines the efficiency of data processing and the quality of subsequent interpretation. The optimal parameters are selected for the seismic data corresponding to a sequence of profiles from the investigated area, and the set of frequencies defined in the first step. The process of the optimal parameters selection is not formal and automatic. Some ideas of how to implement it have been published in papers (Mitrofanov et al., 1998a, 1999, 2001). Its strategy is to select the parameters for the Prony filtration in order to have the best resolution for the target objects for each of the selected frequencies. During this work a priori information about the target horizons is very significant. This information can be obtained from the nearby wells.

3. Seismic data processing, mapping and interpretation of the zones with frequency-dependent response. This processing is based on the optimal parameters selected for several tested lines from the second stage. As a result, we have a complete set of processed profiles, filtered by the Prony method and responding to selected frequencies. This set is the basis for mapping areas with different frequency-dependent response. At this stage we use the information about the line of correlation of the target horizon. As a rule, for the correct mapping and subsequent interpretation, we need to know approximate length of the time interval containing reflections from the target layers and possible top of the target horizon. In this case, we can accurately define short-time intervals for the esti- 

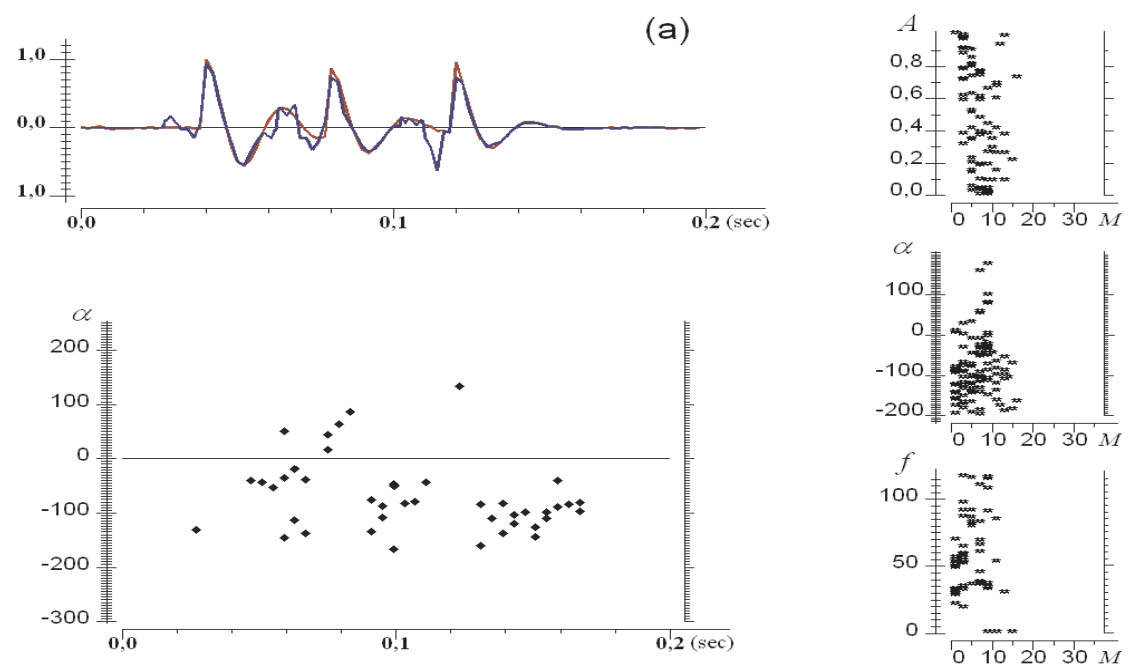

(b)
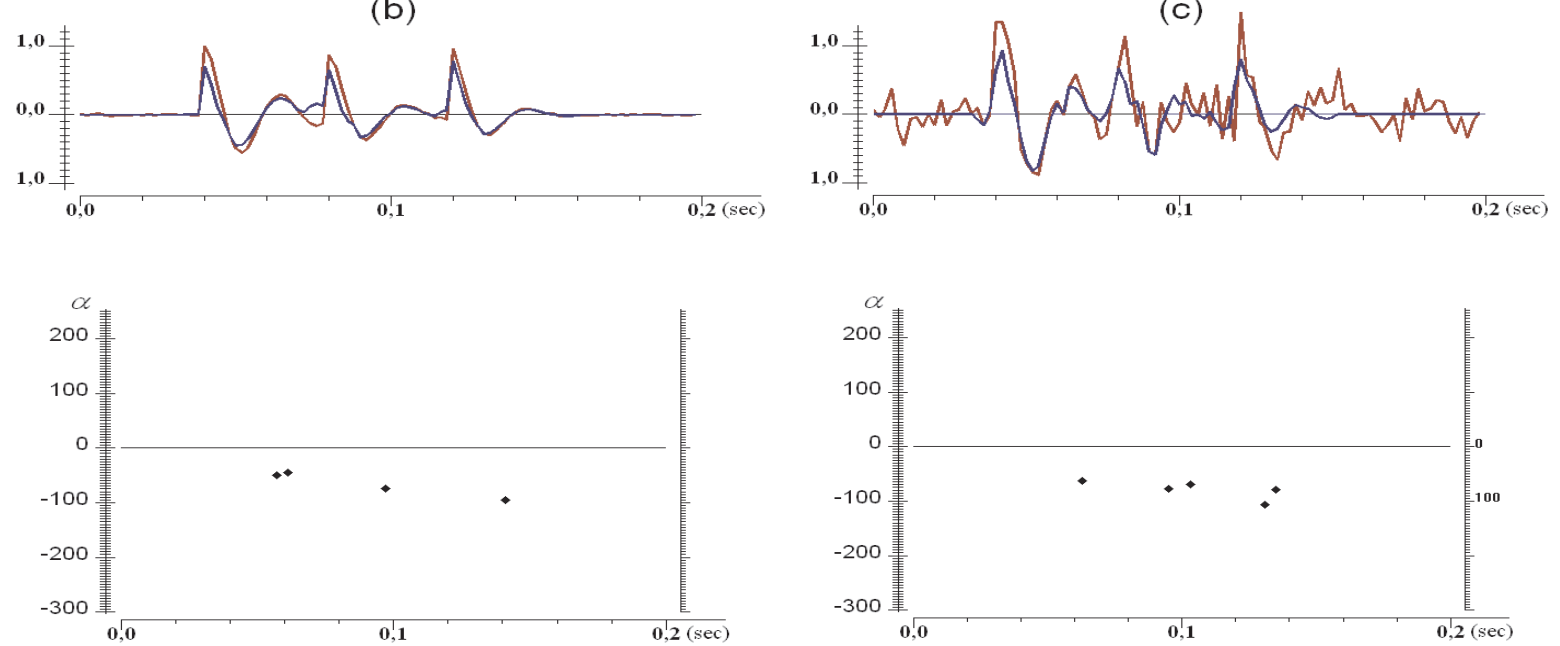

Figure 12 - Estimation of damping component and its parameter attenuation for few signals on the bases of the Prony filtration procedure: result without (a) and after filtration, when noise is absent (b) and middle level of noise is equal 0.35 from signal (c).

mation of Prony dynamic parameters on the basis of the available results of Prony filtration. These parameters are used to make corresponding maps. Various combinations of the dynamic parameters can be used during such mapping. For instance, we can use the relationship between the values of dynamic parameters for different frequencies or time intervals. The choice of combinations is depended on the data and tasks which have to be solved.

Note that the image of stack obtained after the Prony filtration contains more information for the analysis than we could obtain using standard procedures of bandpass filtering. Such images, constructed on set of frequencies, can be called Prony stacks. Analysis of Prony stacks corresponding to different frequencies gives additional information about top and structure of studied reservoir. For instance, the short and strong response at high frequencies is a typical characteristic of a good cover of the reservoir. Moreover, we can observe variations of the properties at different frequencies for thin-layer objects. At the same time a high resolution of Prony stacks allows to study details of these objects, for example, areas of bed thinning into a sedimentary unit.

Thus, if we want to preserve all information about Prony filtration results for the maps construction, we need to use several dynamic parameters. We can recommend using three of them:

- Mean value of interval energy;

- Parameter of exponential decay;

- Degree of coherence between adjacent traces. 
The mean value of interval energy, which gives the most stable result, is the most commonly used in practice.

In previous published works (Mitrofanov et al., 2001, 2003b, 2005; Mitrofanov \& Priimenko, 2007) we illustrated some aspects of the application of Prony technology for synthetic and real data. It was shown that the Prony filtration helps to localize the regions of absorption of the seismic energy in the observed wave field, which may be correlated with the corresponding characteristics of the medium. As a rule, the location of such areas in the high-frequency domain seems the most interesting for further step of interpretation. Real data processing confirms effectiveness of the Prony algorithm to such areas with anomalous absorption/dispersion, which may be associated with the presence of oil/gas reservoir.

Another important feature associated with the analysis of the characteristics of the target horizon should be considered. Until recently, such an analysis was carried out qualitatively, so filtering results of seismic time sections for different frequencies were presented and analyzed by sight only. Based on these results for the target horizons, we can accurately identify areas with different characteristics of attenuation and dispersion. To illustrate this possibility let us examine the results represented in Figure 13: original time cross-section (Fig. 13(a)) and its Prony image for two frequencies: $43 \mathrm{~Hz}$ (Fig. 13(b)) and $60 \mathrm{~Hz}$ (Fig. 13(c)). It is evident that a change in the frequency of filtration from $43 \mathrm{~Hz}$ to $60 \mathrm{~Hz}$ makes it possible to identify a sufficiently large anomalous zone with the increased characteristics of scattering and absorbing the seismic energy in the region of the target horizon (green line). This zone is connected with one of two wells, located on the line of the corresponding profile. It is necessary to note that the Prony filtration was used here with the goal to understand the cause of significant difference in the production features of these wells. For a relatively small distance between the wells $(\sim 800 \mathrm{~m})$ well W1 was dry and well W2 had high production features (to $500 \mathrm{~m}^{3}$ of oil per day). The subsequent interpretation of the Prony filtration results allowed creating a model of the reservoir with the regions of possible channels of hydrocarbon migration from the mother rock of Paleozoic strata to the trap (Fig. 13(d)). The result obtained was presented at the XXIII General Assembly EGS (Mitrofanov et al., 1998a). It demonstrated the possibility of using the method for the solution of geological problems.

Figure 13 also illustrates possibilities of the Prony filtration in the analysis of thin-layer structures of the medium. The transition to high frequencies improves resolution of the reflected signals situated in the area (limited by red line) approximately
$20 m s$ above the target horizon (green line) (Fig. 13(a)). We can observe here a non-stable reflection from an internal boundary. This reflection is tracked much better after Prony filtration with frequency $43 \mathrm{~Hz}$ (Fig. 13(b)) and $60 \mathrm{~Hz}$ (Fig. 13(c)) More expressive example of such analysis is represented in Figure 14. These results enable us to improve analysis of the structure of reservoir (located just above the horizon) and its underlying horizons. Thus, according to the original cross-section, horizons $\mathrm{C}$ and $\mathrm{B}$ correspond to two strong reflections. However, from results of Prony filtration obtained for frequency of $54 \mathrm{~Hz}$ it is possible to clearly distinguish four reflections, located between horizons $\mathrm{C}$ and $\mathrm{B}$. These reflections were confirmed with well data. In addition, one could clearly understand how an error occurred while tracing the horizon A. This horizon is accurately identified closely to the borehole. Then there is an artificial lowering of about $20 \mathrm{~ms}$, which gave an error in depth about 40m. Note some deterioration of the results for frequency of $84 \mathrm{~Hz}$, which is related to sharp decrease in SNR for high frequencies.

This approach was used for detailed studies of the target horizons helping, for example, to choose better location of exploration wells. However, in the real data processing it is important to have a quantitative characteristic of the possible anomalous zones and the frequency variations, observed by the results of the Prony filtration. Such an estimate could be based on the interval energy and its combinations (Brekhuntcov et al., 2001; Mitrofanov et al., 2003a, 2005). It leads to the creation of maps of the anomalous zones of oil/gas fields, which can be used to interpret and predict some of the characteristics of the target horizons. Consider one of the first maps, which illustrate this possibility (Fig. 15). This map was constructed for the analysis of a target producing horizon, and the corresponding result was presented at the EAGE 63 ${ }^{\text {rd }}$ Conference (Brekhuntcov et al., 2001). On the map, in addition to the anomalous zones that characterize different attenuation and absorption of seismic energy at high frequencies (regions with high attenuation and absorption have an intense red color), zones with possible consolidation of the medium (blue color) are shown. The consolidation zones were also determined using the Prony filtration method. In the process of interpretation of this map a structural plan of the horizon and the position of wells with their general production features were given too. It is evident that production wells properties are well correlated with zones of high attenuation and absorption of seismic energy at high frequencies. At the same time, the structural plan of the horizon cannot guarantee the same production characteristics even for relatively closely located wells. For example, wells W10, W3 and W5 are almost at the same level, as well W11 is even in 


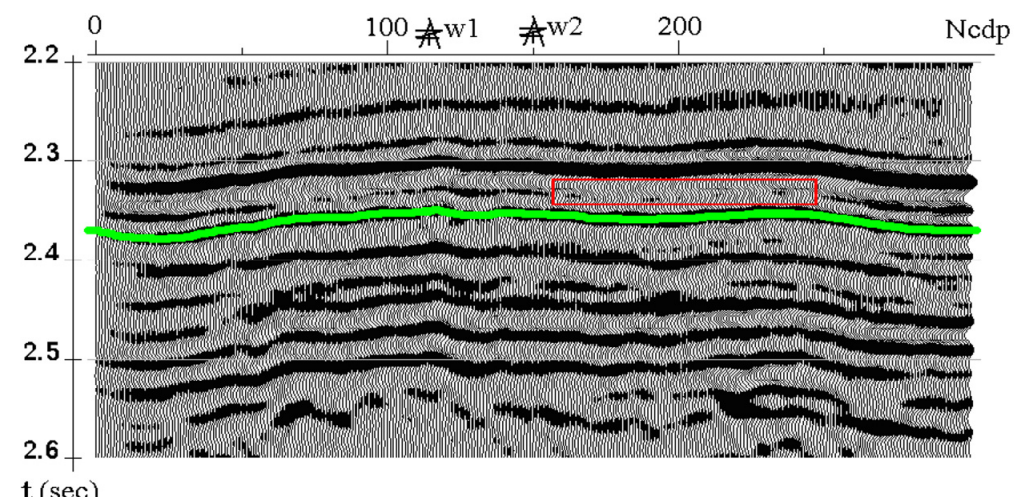

(a)

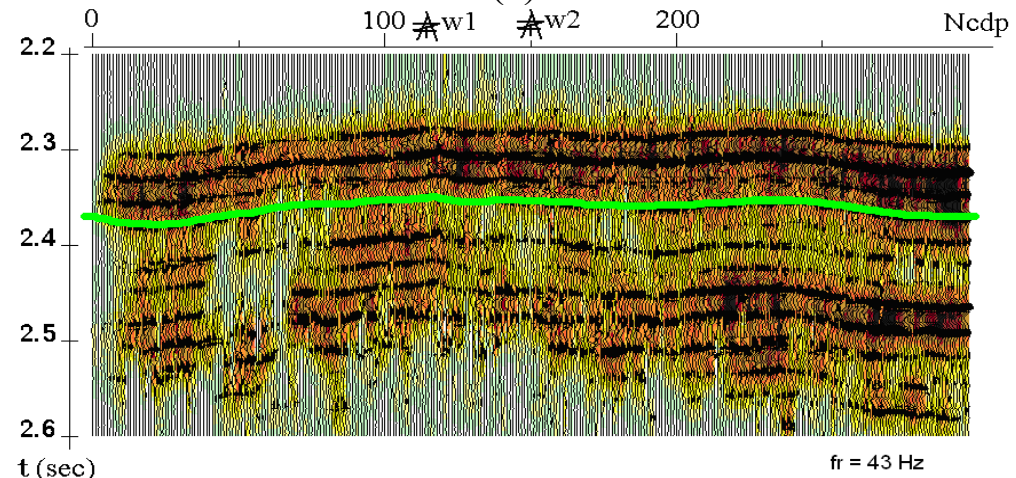

(b)

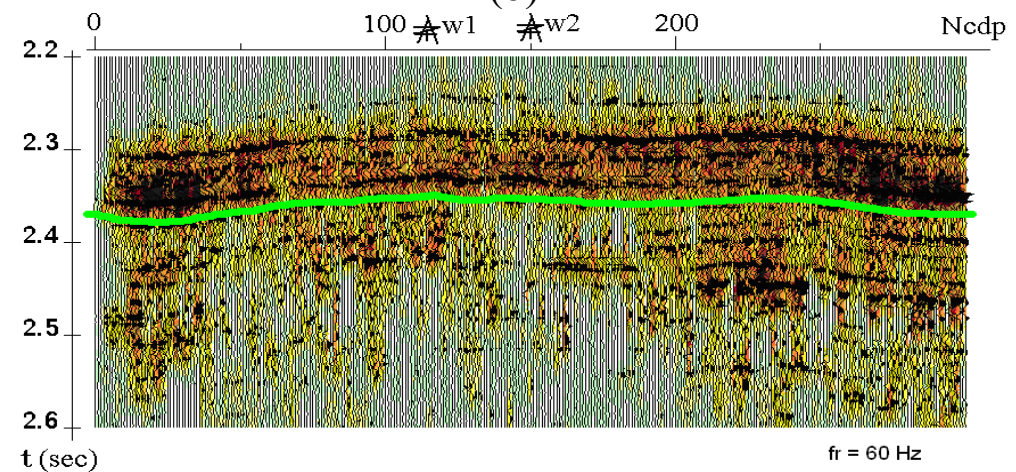

(c)

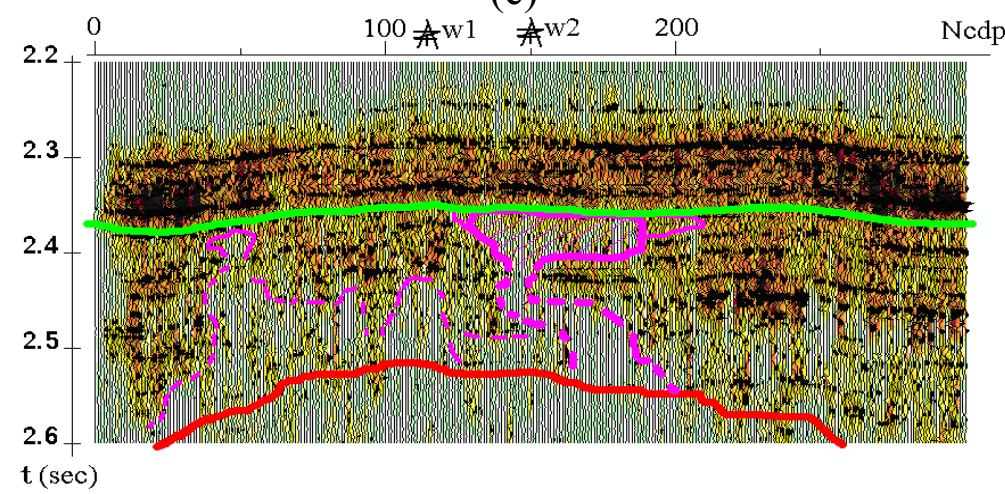

(d)

Figure 13 - Cross-section image after the Prony filtration and its interpretation. 


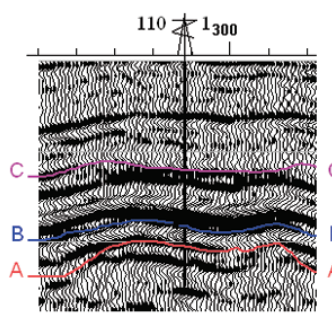

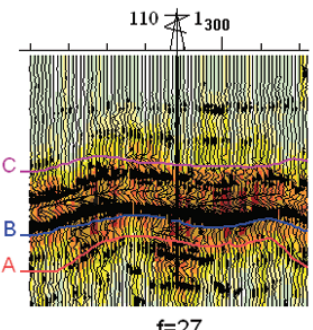

$f=27$

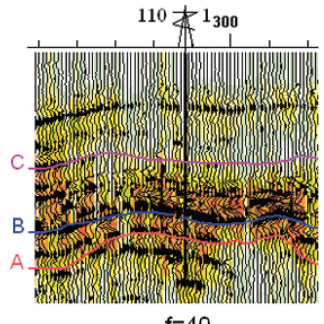

$f=40$

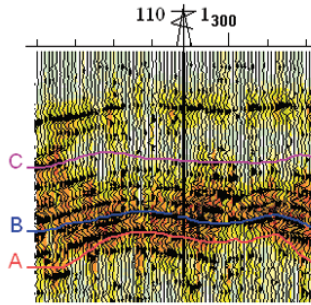

$f=54$

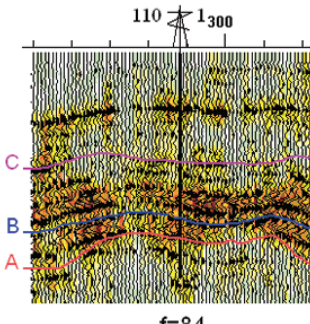

$f=84$

Figure 14 - Analysis of thin-layer structures based on the Prony filtration.

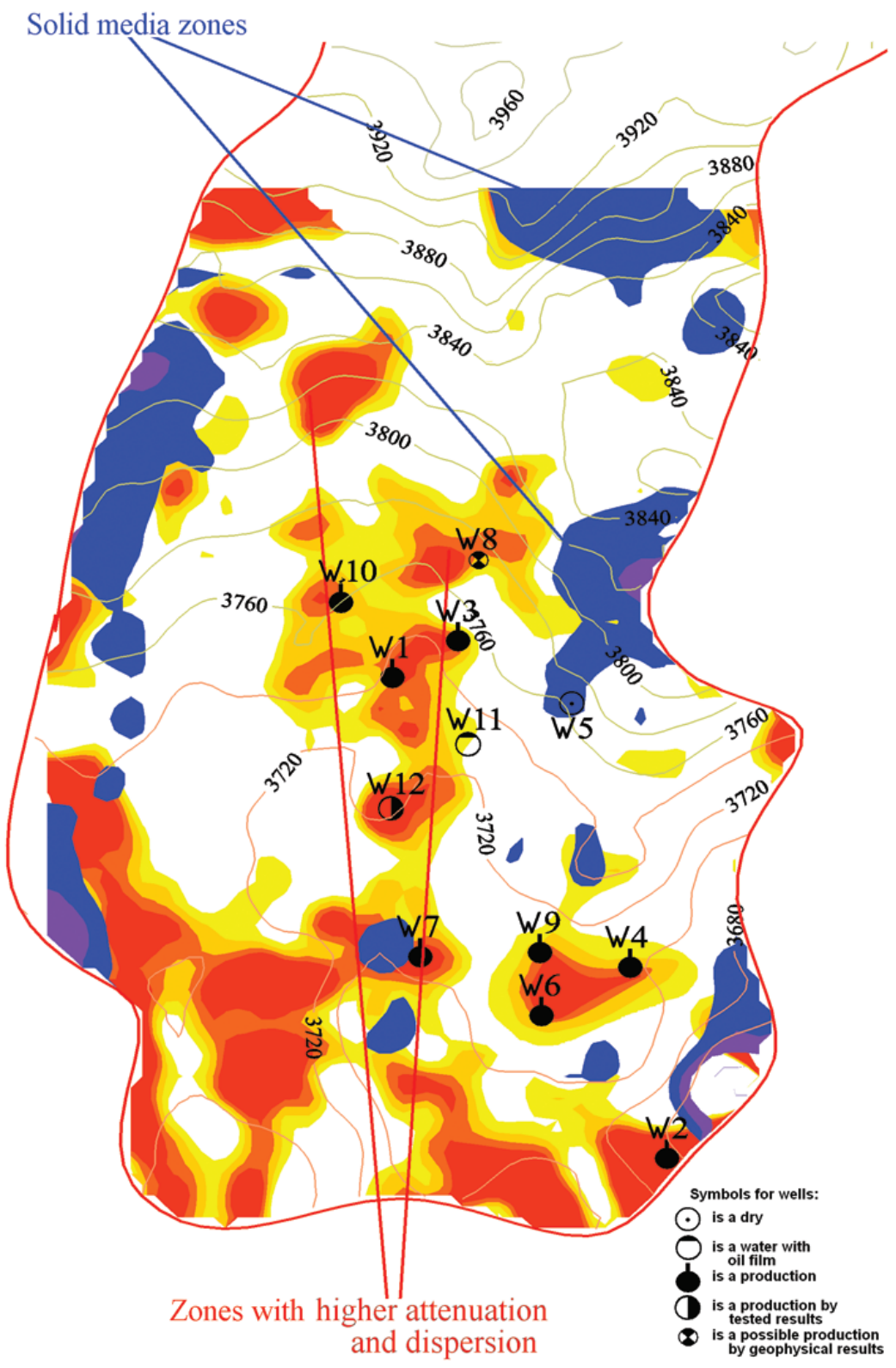

Figure 15 - An example of map for the target horizon features analysis constructed on the basis of the Prony filtration method. 


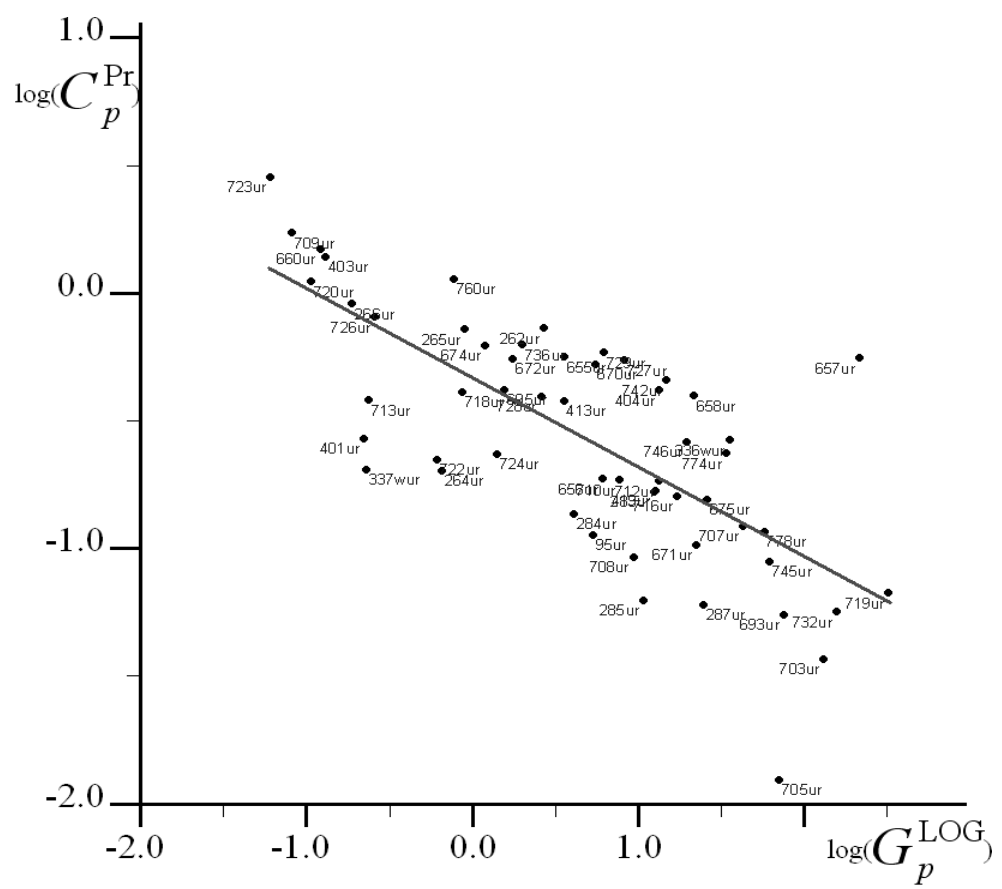

Figure 16 - An example of ratio between the combined Prony parameter $\left(C_{p}^{\mathrm{Pr}}\right)$ and generalized LOG-parameter $\left(C_{p}^{\mathrm{LOG}}\right)$.

better conditions on the structural plan. But all four of these wells have different production characteristics. The results obtained by the Prony filtration method also point to that. It is interesting that the position of well W12 was chosen based on the Prony filtration results. The well testing shown that it is the production.

Thus, use of the interval energy characteristics defined by the Prony filtration results made it possible to move to the formal presentation of the obtained results. However, these characteristics were not linked to the well data, and not allowed to interpret the results in terms of the well data. As a result, maps of the dynamic Prony parameters were analyzed without taking into account the well data. Analysis of a possible link between these parameters and well data can be effective for the study of local reservoir structures, which may be key for characterization of thin-layer objects.

In principle, using the Prony filtration technology for analysis of the target horizons, we can construct maps based solely on the filtration results for different frequencies. However, if there is additional well information, it is advantageous to use it in full. It is a way to create maps of the producing characteristics of the target horizons on the basis of combined Prony parameters (Mitrofanov et al., 2005; Mitrofanov \& Priimenko, 2007). It provides an opportunity to improve the quality and reliability of prediction features of the method. Using the well information can be achieved by linking the combined Prony parameters with well data. As one example of such a relationship we consider correlation between combined Prony parameters, built on the interval energy characteristics $\left(C_{p}^{\mathrm{Pr}}\right)$, and generalized Log-parameter, constructed using the results of well logging $\left(C_{p}^{\mathrm{LOG}}\right)$ (Fig. 16), (Fedortsov et al., 2004). It shows the ratio between the logarithms of the combined Prony parameter and the generalized LOG-parameter. The correlation coefficient in this case is 0.72 . On the basis of this ratio prediction maps of producing characteristics of target horizons were created. The results were tested on a larger number of independent well data and gave good quality predictions for the entire area of study.

We suggest that the Prony filtration method has good perspectives for the analysis and localization of zones with different attenuation and dispersion characteristics. When these areas correlate with target horizons and tested wells, the high accuracy characteristics of oil/gas reservoirs or carbonate bodies or fault zones can be given. In addition, by analyzing high-frequency response and correlation with well data the method can determine some properties of the rock, which are not so easy to evaluate using surface seismic data. Thus, it contributes to modern seismic data processing.

\section{CONCLUSIONS}

We presented a new method for seismic data processing and technology of its use in solving geological and field tasks. This 
method is based on the Prony decomposition and selection of components of this decomposition in order to obtain images of seismic data corresponding to a narrow band of frequencies. Therefore, the method can be called Prony filtration. Its closest analogue is a bandpass filtration. However, Prony filtration method provides higher resolution of signal image with respect to the time variable. Also, the method allows to obtain a damping parameter corresponding to the frequency of filtration. This makes it possible to investigate changes in the damping parameter as a function of the frequency.

Special attention was paid to three points: (i) theoretical foundations of the Prony decomposition to obtain stable estimates of the Prony spectra for signals similar to seismic ones; (ii) use of Prony spectra in the signal filtration processing, i.e., construction of the Prony filtration algorithms; and (iii) description of the Prony filtration technology and examples demonstrating its capabilities in practice. Using simple examples, we introduced basic ideas of the technology, illustrating the main points that are important for the application of this method in the real seismic data processing. The results show good stability of the algorithm for different waveforms and in the presence of other signals and noise. We hope that this approach attracts the attention of specialists to the nonlinear Prony filtration method, as well as to aspects of its implementation in geophysical spectral analysis.

\section{ACKNOWLEDGMENTS}

This work was supported by the Petrobras Institute for Research and Development - CENPES, RJ, Brazil. The first author is especially thanks to the State University of Norte Fluminense Darcy Ribeiro, RJ, Brazil, for providing support as a visiting researcher in LENEP/CCT/UENF. We also are thankful to Dr. Natalia Ruppert and the anonymous referees for helpful suggestions and comments.

\section{REFERENCES}

BATH M. 1974. Spectral Analysis in Geophysics (Development in Solid Earth Geophysics). Elsevier, Amsterdam, 563 pp.

BERTI E, CARDOSO V, GONZALEZ JA \& SPERHAKE U. 2007. Mining information from binary black hole mergers: a comparison of estimation methods for complex exponentials in noise. Physical Review, D75, 124017, $17 \mathrm{pp}$.

BEYLKIN G \& MONZÓN L. 2005. On approximations of functions by exponential sums. Appl. Comput. Harmon. Anal., 19: 17-48.

BRACALE A, CARAMIA P \& CARPINELLI G. 2007. Adaptive Prony method for waveform distortion detection in power systems. Electrical Power and Energy Systems, 29: 371-379.
BREKHUNTCOV A, ILEIN Yu, JEDKOV A \& MITROFANOV G. 2001. Prediction of Production Features on Prony-filtration Results. In: Extended Abstract of Papers, EAGE $63^{\text {rd }}$ Conference \& Exhibition, Amsterdam, 345-348.

CHUI CK. 1992. Wavelet Analysis and its Applications, Vol. 1, 2. San Diego: Academ. Press Inc., 723 pp.

DE PRONY GR. 1795. Essai éxperimental et analytique: sur les lois de la dilatabilité de fluides élastique et sur celles de la force expansive de la vapeur de l'alkool, à différentes températures. Journal de l'École Polytechnique, 1(22): 24-76.

FEDORTSOV VK, BAZHANOVA EV, ILEIN YU \& MITROFANOV GM. 2004. Solution of some application tasks under studying of NGK reservoirs on the basis of wave fields decomposition by the Prony method. Gornye Vedomosti, Tyumen, 3: 81-85. (In Russian).

HAMMING RW. 1989. Digital Filters. $3^{\text {rd }}$ ed. Englewood Cliffs, NJ: Prentice Hall, 296 pp.

HELLE HB, INDERHAUG OH, KOVALJEV VP, MADATOV AG \& MITROFANOV GM. 1993. Complex seismic decomposition - application to pore pressure prediction. In: Extended Abstract of Papers, EAGE 55 ${ }^{\text {th }}$ Conference \& Exhibition, Stavanger, 132-139.

HOLMSTRÖM K \& PETERSSON J. 2002. A review of the parameter estimation problem of fitting positive exponential sums to empirical data. Appl. Math. Comput., 126: 31-61.

KAHN M, MACKISACK MS, OSBORNE MR \& SMYTH GK. 1992. On the consistency of Prony's method and related algorithms. Journal of Computational and Graphics Statistics, 1: 329-349.

KOVALJEV VP \& TELEPNEV GF. 1981. Method of implicit periodicity in study of dynamic problems of seismic waves. Reports of Ukrainian Academy of Sciences, 5: 38-47. (In Russian).

KOVALJEV VP, MADATOV AG \& MITROFANOV GM. 1992. Complex convolution decomposition (CCD) and new possibilities at detail investigation of attenuation. In: Extended Abstract of Papers, EAGE 54 $4^{\text {th }}$ Conference \& Exhibition, Paris, 267-275.

KUMARESAN R. 1983. On the zeros of the linear prediction-error filter for deterministic signals. IEEE Trans. Acoust. Speech Signal Process, 31(1): 217-220.

LEE JH \& KIM HT. 2005. Selection of sampling interval for least squares Prony method. Electron. Lett., 41(1): 47-49.

LOBOS T, REZMER J, JANIK P, AMARIS H, ALONSO M \& ALVAREZ C. 2009. Application of wavelets and Prony method for disturbance detection in fixed speed wind farms. Electrical Power and Energy Systems, 31: 429-436.

MARKS RJ. 2009. Handbook of Fourier Analysis \& Its Applications. Oxford University Press, Inc., 772 pp. 
MARPLE JR SL. 1987. Digital Spectral Analysis with Applications. Prentice-Hall, Inc., Englewood Cliffs, NJ, 584 pp.

MARPLE JR SL. 1989. A tutorial overview of modern spectral estimation. In: Int. Conf. Acoustics, Speech and Signal Processing (ICASSP), 4: 2152-2157.

MITROFANOV G \& PRIIMENKO V. 2007. Detecting of unstructured traps using the Prony technology. In: Proceedings, $10^{\text {th }}$ International Congress of the Brazilian Geophysical Society and $7^{\text {th }}$ Latin American Geophysical Conference, Rio de Janeiro, November 19-22, 2007. CD-ROM.

MITROFANOV GM, HELLE HB, KOVALJEV VP \& MADATOV AG. 1993. Complex seismic decomposition - theoretical aspects. In: Extended Abstract of Papers, EAGE 55 $5^{\text {th }}$ Conference \& Exhibition, Stavanger, 235-242.

MITROFANOV GM, NEFEDKINA TV \& GIRSHGORN LSH. 1998a. Aspects of Proni-transformation applying in seismic data processing. Annales Geophysicae, p. 156, Part I, Supplement to Volume 16.

MITROFANOV GM, ZHITIAN Z \& JIAMING C. 1998b. Using the Proni transform in processing of Chinese seismic data. In: Extended Abstract of Papers, SEG 68 ${ }^{\text {th }}$ Annual Meeting. CD-ROM.

MITROFANOV GM, ORLOV YA, RAKHMENKULOVA IF \& KURDUJKOVA TV. 1999. Testing the Proni filtering by model data. In: Extended Abstract of Papers, EAGE 61 ${ }^{\text {st }}$ Conference, Helsinki. CD-ROM.

MITROFANOV GM, NEFEDKINA TV, BOBRYSHEV AN, SAVIN VG \& POPOV VG. 2001. Applying of the Prony filtration for seismic wave fields analysis with the purpose of perspective zones determination in exploration of oil/gas reservoirs. Geofizika, The Jubilee volume " $50^{\text {th }}$ Khantymansiiskgeofizika", 92-100. (In Russian).

MITROFANOV G, PRIIMENKO V \& SOARES FILHO D. 2003a. Development of the Proni filtering method. In: Proceedings, $8^{\text {th }}$ Interna- tional Congress of the Brazilian Geophysical Society and $5^{\text {th }}$ Latin American Geophysical Conference, Rio de Janeiro, September 14-18, 2003. CD-ROM.

MITROFANOV G, PRIIMENKO V, SOARES FILHO D, MISSÁGIA R, GROCHAU M \& LIMA R. 2003b. Using the Proni filtration in geological and production tasks. In: Proceedings, $8^{\text {th }}$ International Congress of the Brazilian Geophysical Society and $5^{\text {th }}$ Latin American Geophysical Conference, Rio de Janeiro, September 14-18, 2003. CD-ROM.

MITROFANOV G, PRIIMENKO V, MISSÁGIA R, DA SILVA F \& SOARES FILHO D. 2005. Determination of reservoir features by using the Prony filtration and Log-parameter ratios. In: Proceedings, $9^{\text {th }}$ International Congress of the Brazilian Geophysical Society, Salvador, Brazil, September 11-14, 2005. CD-ROM.

OSBORNE MR. 1975. Some special nonlinear least squares problems SIAM Journal of Numerical Analysis, 12: 571-592.

OSBORNE MR \& SMYTH GK. 1991. A modified Prony algorithm for fitting functions defined by difference equations. SIAM Journal on Scientific Computing, 12: 362-382.

OSBORNE MR \& SMYTH GK. 1995. A modified algorithm for exponential functional fitting. SIAM Journal on Scientific Computing, 16: 119-138.

POTTS D \& TASCHE M. 2009. Parameter estimation for exponential sums by approximate Prony method. Signal Processing, 90: 1631-1642.

RIBEIRO M, EWINS D \& ROBB D. 2003. Non-stationary analysis and noise filtering using a technique extended from the original Prony method. Mechanical Systems and Signal Processing, 17(3): 533-549.

THERRIEN CW. 1992. Discrete Random Signals and Statistical Signal Processing. Englewood Cliffs, NJ: Prentice Hall, 727 pp.

\section{NOTES ABOUT THE AUTHORS}

Georgy Mikhailovich Mitrofanov graduated in Geology and Geophysics, Novosibirsk State University, Akademgorodok, Novosibirsk, Russia, in 1972. He received his Ph.D. in Mathematical Physics in 1984. He is currently a visiting professor of the Laboratory of Petroleum Engineering and Exploration, State University of Norte Fluminense Darcy Ribeiro, Macaé, RJ, Brazil. Areas of interest: seismic data processing, direct and inverse problems in geophysics, reservoir characterization.

Viatcheslav Ivanovich Priimenko graduated in Applied Mathematics and Mechanics, Novosibirsk State University, Akademgorodok, Novosibirsk, Russia, in 1978. He received his Ph.D. in Mathematical Physics in 1990. He is a professor of the Laboratory of Petroleum Engineering and Exploration, State University of Norte Fluminense Darcy Ribeiro, Macaé, RJ, Brazil. Areas of interest: direct and inverse problems in geophysics and petroleum engineering, numerical modeling and migration. 